INTEGRATION OF SURVIVORSHIP CARE PLANS INTO STANDARD CARE: A QUALITY IMPROVEMENT PROJECT

\author{
A Scholarly Project \\ submitted to the Faculty of the \\ Doctor of Nursing Practice Program \\ of Georgetown University \\ in partial fulfillment of the requirements for the \\ degree of Doctor of Nursing Practice
}

By

Patricia E. Deslauriers, M.S.N.

Washington, DC

November 18, 2016 


\title{
INTEGRATION OF SURVIVORSHIP CARE PLANS INTO STANDARD CARE: A QUALITY IMPROVEMENT PROJECT
}

Patricia E. Deslauriers, M.S.N.

Thesis Advisor: Jane Fall-Dickson, Ph.D.

\begin{abstract}
American College of Surgeons' Commission on Cancer accredited programs are required to provide Survivorship Care Plans (SCPs) to cancer survivors after initial cancer treatment. A critical need exists to evaluate SCP patient outcomes. The primary purpose of this DNP scholarly project was to integrate SCPs into standard care for adult stage I, II, and III breast and colon cancer patients. Secondary aims were to examine the effect of SCPs on participants' knowledge base regarding their cancer, health promotion and disease prevention, satisfaction with delivery of health care, health-related quality of life (HRQOL), and adherence to follow-up visits and surveillance testing.

The IRB approved study was conducted at a hospital-based medical oncology clinic in the Western United States. A quasi-experimental pre/post design was used. Project data were collected pre/post SCP with the Sociodemographic Form, Clinical Data Forms I and II, Medical Outcomes Study Short Form-36 (MOS-SF-36), Patient Satisfaction Questionnaire Short Form (PSQ-18), and Patient Knowledge of Disease Questionnaire (PKDQ). At the follow-up visit, MOS-SF-36, PSQ-18, PKDQ, and open-ended evaluative questionnaire (OEEQ) data were collected.
\end{abstract}

Forty-two participants were enrolled between March 29, 2016 and August 2, 2016. The sample was primarily female (86\%), white $(97.6 \%)$, Hispanic $(85.7 \%)$, non-high school graduates (61\%), and unemployed/retired (78\%). Annual incomes were primarily less than $\$ 20,000(78 \%)$. 
Participants were status post treatment for breast cancer $(n=35)$ or colon cancer $(n=7)$. All participants returned for follow-up visits. Significant increases in knowledge of disease were observed $(\mathrm{p}<0.001)$ post SCP and at the follow-up visit. No statistically significant changes were seen in MOS-SF-36 and PSQ-18 post SCP. Emerged themes from the OEEQ revealed increased knowledge regarding disease, satisfaction with health care provider encounter, and improvements in patient emotional and physical well-being following integration of SCPs. Integration of the SCP into standard care in this low socio-economic, ethnically diverse sample increased participants' knowledge about their cancer disease process, and promoted adherence to follow-up visits. Results warrant further testing in a fully powered study of longer duration with diverse cancer diagnoses to examine SCP effect on HRQOL and patient satisfaction with delivery of healthcare.

Keywords: Survivorship care plan. Breast cancer. Colon cancer. Low socioeconomic status. Ethnically diverse. Health disparities. Patient satisfaction. Knowledge. 


\section{ACKNOWLEDGEMENTS}

It is with great honor that I have been in the company of so many nursing educators and medical professionals who have been my role models, inspiration, and support throughout my educational journey. I am indebted to the wonderful staff members at my workplace, who supported and assisted me throughout this project. Francine Sanchez, Theresa Marin, Lori Vanderweit, RN, Gloria Ross, and Julie Aguilar were instrumental in assisting me with the success of this project. I appreciate the health care providers at my work place who supported my educational endeavor and covered my patient load during my many absences while away at Georgetown University. Thank you, Dr. Shanmuga Subbiah for shadowing my project and giving salient advice.

I want to thank all of the professors at Georgetown University School of Nursing \& Health Studies who challenged me, guided me, and encouraged me, every step of the way. I want to extend my utmost appreciation to Dr. Peggy Slota who became the DNP Program Director, School of Nursing \& Health Studies, during a crucial period of time during my doctoral education. She was a guiding light - encouraging, empowering, and inspiring me to fulfill my dream. A sincere thanks goes to Dr. Nancy Crowell for providing statistician support and expertise. To my classmates, thank you for your friendship, support, and the strength that you have given throughout this amazing adventure. I will never forget you. And finally, I want to thank Dr. Jane Fall-Dickson for her amazing wisdom, guidance, and inspiration as my faculty mentor throughout this project. I could not have done it without her! From the bottom of my heart, thank you all, so very much. 


\section{DEDICATION}

I dedicate the culmination of my educational journey with the Doctor of Nursing Practice to the loves of my life. To my mother, Lois Carrington, whose own tenacity taught me to never quit; to my late father, Roger Clay, who, in his life, always encouraged me to reach for my dreams; to my children, Dr. Linda Wegley Kelly and Dr. Brian Wegley, who I admire so very much for all that they have accomplished, while overcoming life's obstacles along their educational journeys, and love with all my heart; to my grandsons, Brendan and Aidan Kelly, who have taught me to love unconditionally and light up my life; and to George Ash, my love, who provided never-ending support, encouragement and love throughout this journey. My heartfelt thanks to all of you for your loving support and understanding for all of the special times I missed while pursuing my dream. I love you all, so very much! 


\section{TABLE OF CONTENTS}

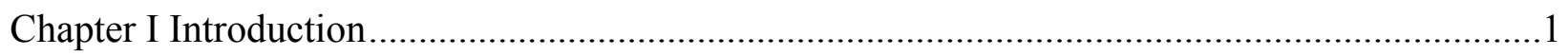

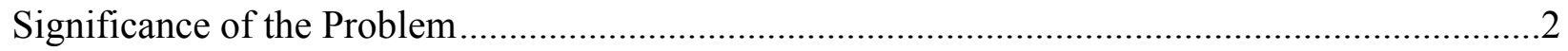

Organizational Needs Assessment: Facilitators and Barriers .........................................3

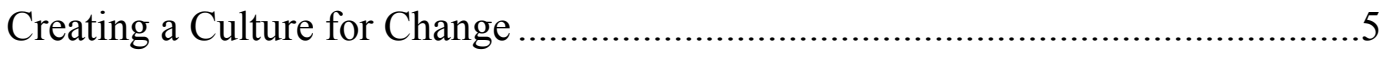

Overcoming Barriers for a Successful DNP Scholarly Project ..........................6

Implementation and Sustainability of the Evidence-Based Practice Change ..........7

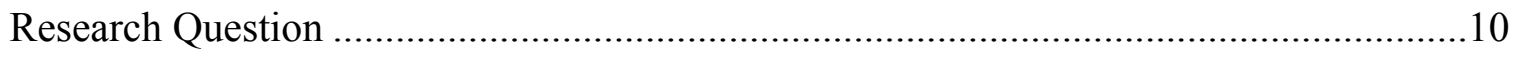

Theoretical and Conceptual Frameworks .............................................................11

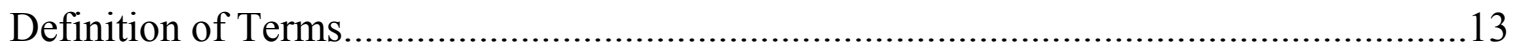

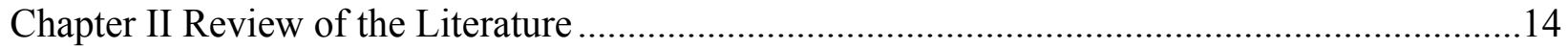

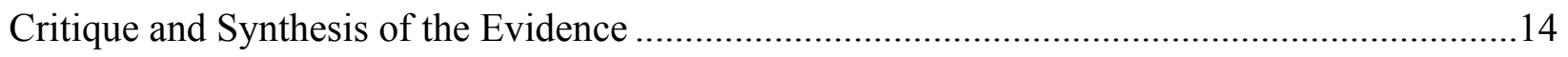

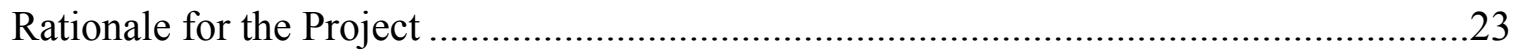

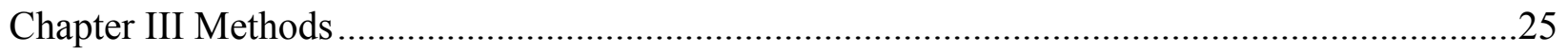

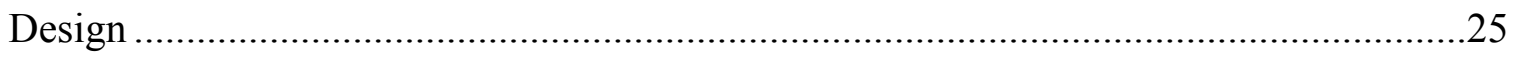

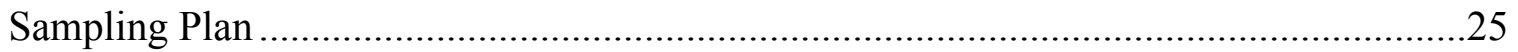

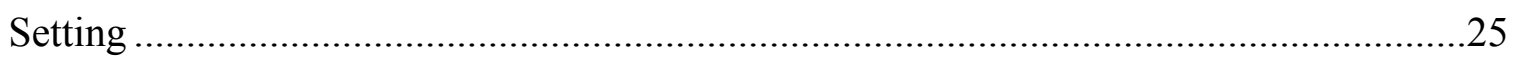

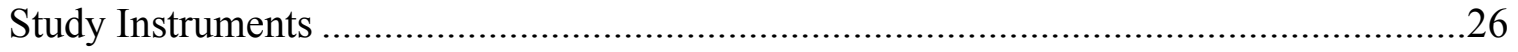

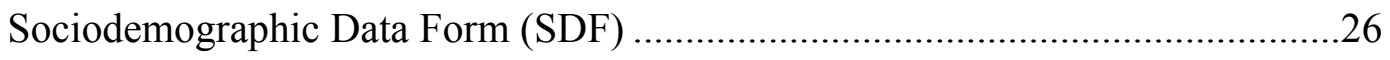

Clinical Data Form I (CDFI) ...............................................................26

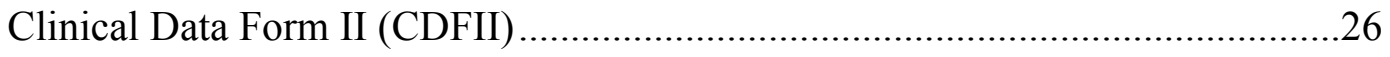

Medical Outcomes Study Short Form-36 (MOS-SF-36) .................................26

Patient Satisfaction Questionnaire Short Form (PSQ-18) ...............................27 
Patient Knowledge of Disease Questionnaire (PKDQ) ....................................27

Open-Ended Evaluation Questionnaire (OEEQ) ..........................................27

Survivorship Care Plan (SCP) Intervention ....................................................28

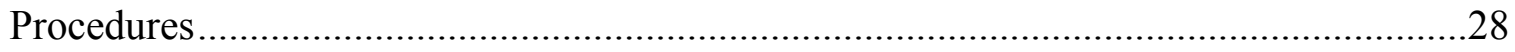

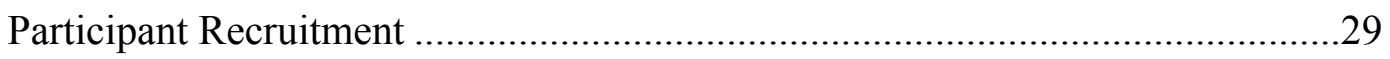

SCP Intervention and Questionnaires' Administration .....................................29

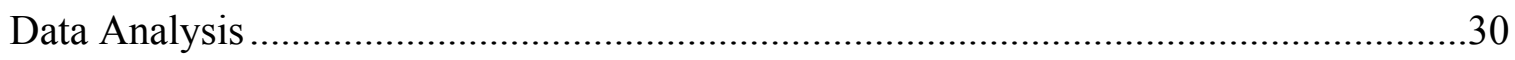

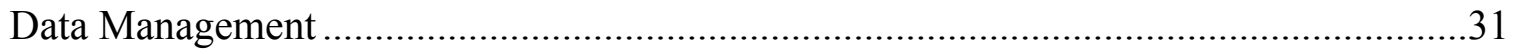

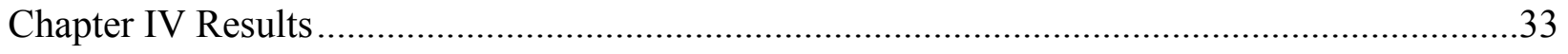

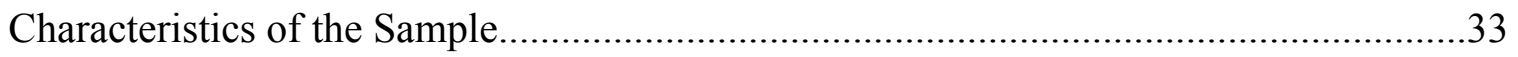

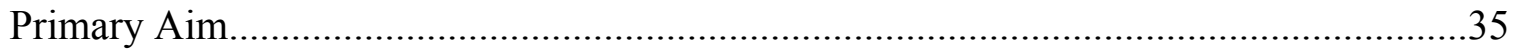

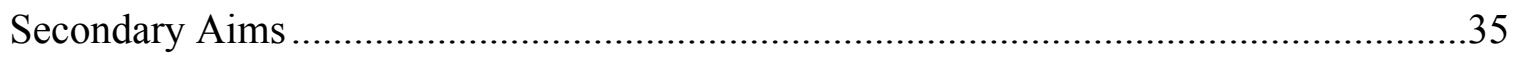

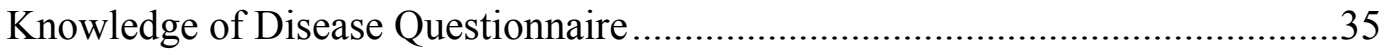

Medical Outcomes Study Short Form-36 (MOS-SF-36) Questionnaire ...............37

Patient Satisfaction Questionnaire - Short Form (PSQ-18) .............................37

Adherence to SCP Follow-up Visits and Surveillance Tests ...............................37

Open-Ended Evaluative Questionnaire (OEEQ) ..............................................38

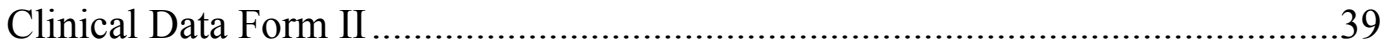

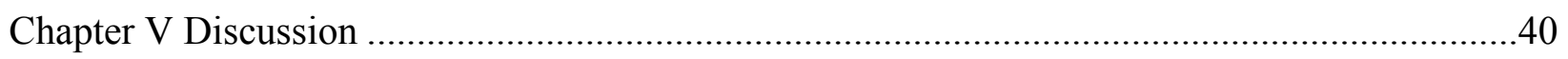

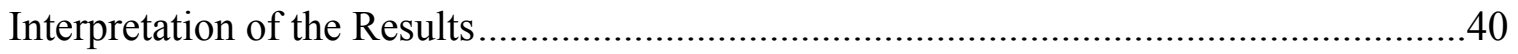

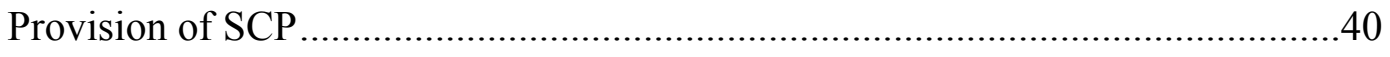

Compliance with Follow-up and Diagnostic Testing ....................................41

Patient Knowledge of Disease Questionnaire .................................................41 
MOS-SF-36 and PSQ-18 Questionnaires ....................................................42

Open-Ended Evaluative Questionnaire (OEEQ) ............................................42

Clinical Data Form II ..........................................................................4

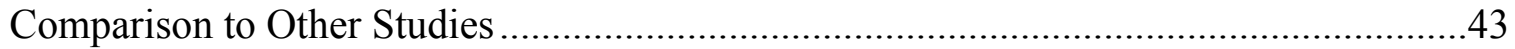

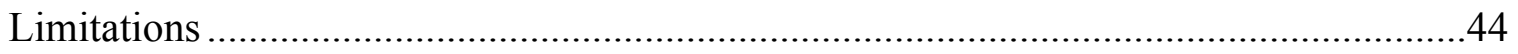

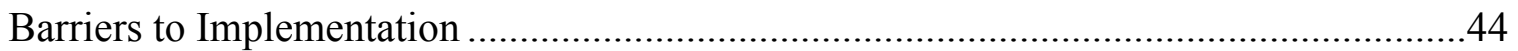

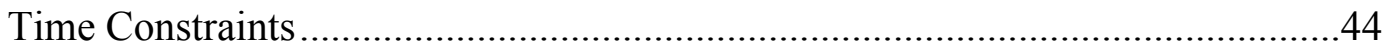

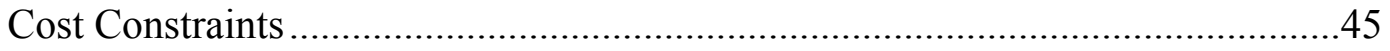

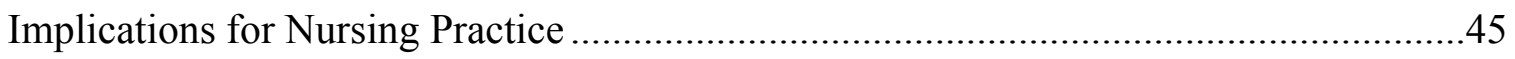

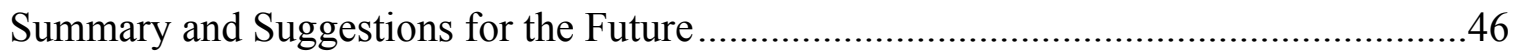

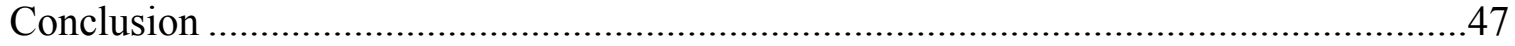

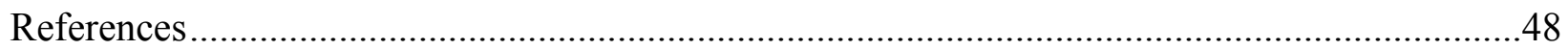




\section{LIST OF FIGURES}

Figure 1. Education Level..................................................................................................

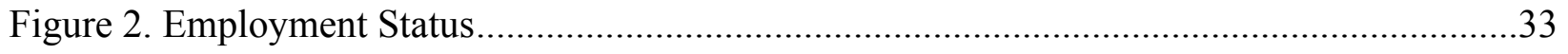

Figure 3. Emerged Themes from OEEQ-Question 1 …..........................................................

Figure 4. Emerged Themes from OEEQ-Question 2 …………………...................................38 


\section{LIST OF TABLES}

Table 1. Barriers, Interventions, and Outcomes of the Quality Improvement Project ..................6

Table 2. Donabedian Model Elements within the DNP Scholarly Project Model.......................12

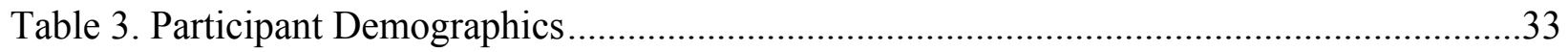

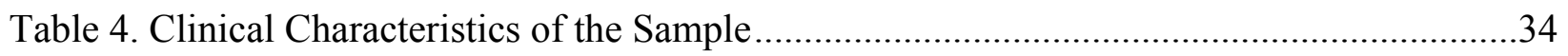

Table 5. Comparison of PKDQ Percentage Correct from Pre-to Post- SCP Intervention to

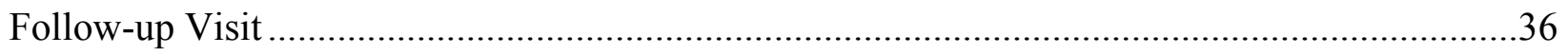

Table 6. PKDQ Correct Answers Pre, Post, and Follow-up (F/U) ..........................................36

Table 7. MOS-SF-36 Subscale Scores from Pre- to Post- SCP Intervention ................................37

Table 8. PSQ-SF-18 Subscale Scores from Pre- to Post- SCP Intervention.................................37 


\section{Chapter I}

\section{Introduction}

Cancer survivorship is recognized widely as an important distinct phase of the cancer care continuum, as noted in the 2005 Institute of Medicine (IOM) report "From Cancer Patient to Cancer Survivor: Lost in Transition" (Hewitt, Greenfield, \& Stovall, 2006). The annual incidence for all cancer diagnoses in the United States (US) is 1.9 million with an estimated $65 \%$ of all cancer patients living five years from diagnosis (Weir, Thompson, Soman, Møller, \& Leadbetter, 2015). It is estimated that by 2020 there will be 18 million cancer survivors in the US, which represents an increase of 31\% from 2010 (Mariotto, Yabroff, Shao, Feuer, \& Brown, 2011).

Cancer survivorship is complicated by increased risks of long-term morbidity and premature mortality due to long-term side effects of cancer treatment, exacerbation of coexisting co-morbidities, and the cancer itself (McCabe, et al., 2013). Health care professionals play an important role in recognizing importance of risk assessment and preventative services for cancer survivors (McCabe, et al.) Although a 2004 American Society of Clinical Oncology (ASCO) survey found that three-quarters of oncologists reported that they should be involved in ongoing health maintenance, screening, and preventative care for cancer survivors, $60 \%$ of respondents reported that they felt uncomfortable providing these services (Ganz, 2006). This finding may be related to the paucity of research to support the evidence base for cancer survivorship care strategies delivered by health care professionals. Thus, there is a critical need to develop, test, and evaluate outcomes of professional care strategies for cancer survivors to build the evidence base for this care (Cowens-Alvarado, et al. 2013). One such care strategy is the patient-specific survivorship care plan (SCP) presented in the 2005 IOM report. 
The IOM (2005) recommended that this SCP, which includes a treatment summary (TS) and follow-up care plan, be developed and provided to all cancer survivors at the completion of their initial cancer treatment (Hewitt, Greenfield, \& Stovall, 2006). The SCP is a standardized tool designed to promote delivery of optimal cancer survivor patient-centered care (Mayer, et al., 2014). The SCP summarizes the patient's cancer history, including the following elements: a) cancer diagnosis and stage; b) dates of cancer treatment initiation and completion; c) types of treatment (surgical procedures, radiation therapy, pharmacologic treatment, immunologic treatment); d) potential long-term and latent adverse effects of cancer treatment; e) surveillance testing for recurrence; f) oncology follow-up surveillance visits; and g) support services focusing on psychological support, nutritional and genetic counseling, and health promotion and disease prevention strategies. The SCP drives an open dialogue among the oncology team, the patient, the patient's family members, and the primary health care provider. Cancer survivors' adherence to their individual SCP is a core measure of the ASCO Quality Oncology Practice Initiative (QOPI), and implementation of the SCP is a standard of the 2012 American College of Surgeon's Commission on Cancer (ACS CoC) Programs (Morgan, 2009).

\section{Significance of the Problem}

The ACS CoC (2012) requires that for hospitals to maintain their cancer program accreditation, they must provide SCPs to $10 \%, 25 \%, 50 \%$, and $75 \%$ of their stage I, II, and III cancer patients by years $2015,2016,2017$, and 2018, respectively. The western US county hospital that served as the Doctor of Nursing Practice (DNP) Scholarly Project clinical site provides care to approximately 600-700 newly diagnosed cancer patients annually (Ross, G. personal communication, March 9, 2015). However, historically, only 10\% of the surgical oncology, radiation oncology, and medical oncology patients at this clinical site have received 
SCPs, which is out of compliance with the ACS CoC requirements for cancer program accreditation.

\section{Organizational Needs Assessment: Facilitators and Barriers}

The Medical Oncology Clinic, which is located within the study's hospital-based Oncology Program, is staffed with two medical oncologists, one of which is the Acting Medical Director, and two oncology nurse practitioners. The Radiation Therapy Department has two radiation oncologists. The Surgical Oncology Department includes five surgeons and a team of surgical residents. Additional staff who are involved in cancer care are Cancer Committee members including two tumor registrars and two patient navigators, whose roles are new additions to the Cancer Program.

At the time of this project implementation, the Medical Oncology Department had the greatest unmet need within the Oncology Program regarding integration of the SCPs into standard care following completion of patients' initial intent-to-cure cancer treatment. The Oncology Department is the primary gatekeeper for the majority of the cancer patients who receive intent-to-cure cancer treatment. However, there are some patients who may not see a medical oncologist due to very early cancer diagnosis requiring only surgical resection, and/or radiation therapy.

The Medical Oncology Department sees approximately 45-50 patients per day in the Outpatient Clinic, as well as providing medical oncology in-patient services. Patient demographics include adult, multiethnic cancer patients within one of the lowest socioeconomic counties in the Western US. Many oncology patients depend upon public transportation, which includes city buses, often requiring multiple transfers. This creates added patient scheduling difficulty and tardiness for appointments. The 20 -minute return visit and the 60 -minute new 
patient visit allotted time periods are often exceeded two-fold as healthcare providers address physical, emotional, and psychological aspects of cancer, both with the patient and significant others. The Medical Oncology Clinic has a no-show rate of approximately 16\%. Many patients struggle with comprehending the full extent of their disease due to language barriers and lowliteracy. These barriers provide challenges to the patient-provider office visit.

Additional barriers within the Medical Oncology Department include the time required to implement systematic administrative change. The Medical Director of this department has administrative responsibilities including overseeing Departmental medical decisions, functioning as the primary attending physician for both residents during their oncology training and the oncology nurse practitioners, review of new-patient referrals, resolution of intra-departmental and inter-departmental issues, and attendance at many administrative meetings. Integration of the SCP into standard care required careful planning with buy in from stakeholders and the staff, integration within the patient schedule, and formulation of the SCP content.

The Tumor Registry staff members, the patient navigators, the surgical oncologist, and the DNP student met several times to discuss the initial rollout of the SCPs. The hospital administration had been urging prompt implementation of the SCPs to meet the requirement of the ACS $\mathrm{CoC}$ for cancer program accreditation. At their request, the most appropriate SCP models that have been developed by various cancer organizations were reviewed and the Journey Forward SCP model (Hausman, Ganz, Sellers, \& Rosenquist, 2011) was chosen due to no upload cost, ease of implementation, computer-user friendliness, and satisfaction of all the requirements set by ASCO and the IOM. The tumor registrars requested permission from the hospital Forms Committee to begin implementation of the SCP. 
Creating a Culture for Change. Schein (1984) outlined three stages of an organizational culture's ability to adapt to change. He stated that a culture in its' infancy, forming and growing, is glue-like, very adaptable, malleable and less resistant to change than more advanced stages of an organization's culture. During the organization's midlife, change can occur, but it must be done in a strategic manner and with a good understanding of the culture's stabilizing forces and beliefs, values, and basic assumptions. And finally, mature organizational cultures are the most resistant to change and the change process is often painful.

The culture within the Department of Medical Oncology may be described as a "midlife" culture. The Director of this department has been in the position for about three years and the second medical oncologist has been with the organization for about two years. The ancillary staff members, who schedule the patients, often resist change which is perceived as new and different. However, after they received education on the study project, they showed little resistance to the requested alterations to the schedule. The Cancer Committee members, including the Tumor Registry staff and the patient navigator, have a vested interest in the implementation of the SCP program to promote Oncology Program accreditation through the ACS CoC Program.

Integration of the SCP was facilitated by the dedicated oncology staff, the Cancer Committee members, and C-Suite management team, as well as, the need to maintain ACS CoC accreditation of the Oncology Program. Barriers included scheduling the patient SCP visit within an already busy Medical Oncology Clinic schedule, the Director of the Medical Oncology Clinic's busy schedule, the competing priorities within the oncology staff member's busy schedules and limited resources, the oncology staff members' anxiety about and resistance to 
change, and the patients' social and educational disparities which may negatively impact their understanding of and compliance with follow-up visits.

Overcoming Barriers for a Successful DNP Project. Implementing a successful DNP project requires analysis of practice barriers that need intervention including: 1) Oncology Department scheduling and resource issues, 2) busy C-Suite Medical Director, 3) oncology staff members with perceived anxiety due to the departmental changes, and; 4) patient socioeconomic and educational issues.

According to Shirey (2006), using the model of innovation diffusion theory, the nurse leader is able to be a change agent using the five stages of the theory: knowledge; persuasion; decision; implementation; and confirmation. This model allows the staff members to recognize the issues, be involved in the change process, discuss and evaluate the proposed changes, and have an active role in implementation and evaluation of the results and outcomes. The use of this model assisted the DNP scholar to obtain the largest coalition to adopt and embrace the quality improvement project. Table 1 outlines the identified barriers, proposed interventions and expected outcomes.

Table 1. Barriers, Interventions, and Outcomes of the Quality Improvement Project.

\begin{tabular}{|c|c|c|}
\hline Barrier & Intervention & Outcome \\
\hline $\begin{array}{l}\text { - Scheduling and resource } \\
\text { issues }\end{array}$ & $\begin{array}{l}\text { - Educate the Medical Oncology } \\
\text { Department staff members regarding } \\
\text { study rationale and urgency } \\
\text { - Inform Medical Oncology } \\
\text { Department staff members of need to } \\
\text { block a specific scheduling time for the } \\
\text { DNP scholar }\end{array}$ & $\begin{array}{l}\text { - The patient schedule will reflect } \\
\text { the availability to schedule patients for } \\
\text { their SCP visit }\end{array}$ \\
\hline $\begin{array}{l}\text { - Medical Oncology } \\
\text { Director's demanding } \\
\text { schedule }\end{array}$ & $\begin{array}{l}\text { - Assure the Medical Oncology } \\
\text { Director that his role will be only } \\
\text { oversight and advisory } \\
\text { - He will be informed of all aspects of } \\
\text { change and rationale. He has agreed to } \\
\text { be the mentor to the DNP scholar }\end{array}$ & $\begin{array}{l}\text { - The Medical Oncology Director } \\
\text { provides advice and oversight. } \\
\text { - The Medical Oncology Director } \\
\text { demonstrates positive input and } \\
\text { actions. }\end{array}$ \\
\hline $\begin{array}{l}\text { - Perceived resistance to } \\
\text { change by staff members } \\
\text { within the Medical } \\
\text { Oncology Department }\end{array}$ & $\begin{array}{l}\text { - Educate Medical Oncology } \\
\text { Department staff members regarding } \\
\text { project and rationale } \\
\text { - Encourage discussion and sharing of } \\
\text { ideas to promote change }\end{array}$ & $\begin{array}{l}\text { - The Medical Oncology Clinic staff } \\
\text { members will adopt the new schedule } \\
\text { and openly share new ideas }\end{array}$ \\
\hline
\end{tabular}


- Provide positive reinforcement with incremental changes

- Patient socioeconomic and educational constraints
- Confirm understanding from patient, family and caregivers of the importance of the SCP follow-up appointment.

- Assure that the appointment is scheduled for an appropriate date and time

- Re-schedule missed appointments
- $\quad$ Patients will keep their scheduled follow-up appointments

- There will be a decrease in the noshow rate of the follow-up appointments

- $100 \%$ of missed follow up visits will be rescheduled

Implementation and Sustainability of the Evidence-Based Practice Change. Dang et al.

(2015) reported that practice change needs to be guided by conceptual models or frameworks.

The revised version of the "Model for Evidence-Based Practice Change" by Rosswurm and Larrabee (1999) was used to guide implementation and sustainability of the evidence-based practice change. The eight steps for successful change model by Kotter and Cohen (2012) were integrated into the DNP scholarly project to facilitate change implementation.

Model for evidence-based practice change. The six steps in the revised model by Rosswurm and Larrabee (1999) include: 1) assessing the need for change; 2) locate the best evidence; 3) critically analyze the evidence; 4) design practice change; 5) implement and evaluate change in practice; and 6) integrate and maintain change in practice.

Step one, assessing the need for change, included: 1) assembling a team of key oncology stakeholders including patients, practice providers, support staff and the Tumor Board registrars; 2) collecting and comparing internal and external information regarding the practice which included recognizing the unmet need of non-compliance with cancer program accreditation requirement of the ACS CoC to provide SCPs to stage I, II, and III cancer patients who have completed intent-to-cure therapy; and 3) preparing the problem statement. Step two, locating the best evidence, included: 1) identifying sources of published evidence supporting DNP Scholarly Project implementation including clinical practice guidelines, systemic reviews, randomized controlled clinical trials, national organizations' committee reports (IOM, ACS, ASCO); and 2) 
conducting an extensive literature search for evidence from electronic data bases, journals and books. Step three of preparation included a critical analysis of the evidence: 1) using a table of evidence to appraising the strengths and weaknesses of the published data; 2) synthesizing the best evidence from the table of evidence and evaluating the strength of the body of evidence that supports the practice change; and 3) assessing the feasibility, risks, and benefits of a new practice change within the workplace. Step four, designing practice change, included: 1) defining the proposed change of the integration of SCPs into standard care for adult cancer survivors of stage I, II, and III breast and colon cancer who have completed intent-to-cure treatment at the DNP Scholarly Project's clinical site; 2) identifying resources needed (personnel, data collection forms, equipment, time); 3) designing a pilot study to examine integration of SCPs into practice; and 4) designing the implementation plan for the DNP Scholarly Project including obtaining institutional review board approval, reaching out to project champions, and informing and educating the oncology team at the clinical practice site. Step five, implementing and evaluating change in practice, included: 1) integrating SCPs into standard care for stage I, II, and III breast and colon cancer patients within the oncology practice, 2) conducting ongoing evaluation of the process and outcomes; and 3) evaluating SCP integration process and formulating conclusions and embracing recommendations from ongoing feedback from colleagues and ancillary staff members. And finally, step six, integrating and maintaining practice change is currently ongoing and includes: 1) communicating the findings to the C-suite management team, stakeholders, and project champions; 2) planning integration of SCPs into all oncology patients' plan of care; 3) continually monitoring the process and outcomes; and 4) disseminating the results of the evidence-based project to the community, locally and nationally. 
The heart of change: Eight steps for successful change. For the successful implementation of the project, it was important to understand the impact of change within an organization. Change in any organization can be stressful. To reduce the barriers that can interfere with the successful implementation of the project, a change theory is needed to facilitate the change process. Kotter and Cohen (2012) outlined eight steps for a successful organizational change. First, it is important to create a sense of urgency, especially within organizations that are in the complacency mode. Articulating the need to integrate the SCP into standard care for all oncology patients to the oncology team to maintain ACS CoC cancer center accreditation made a strong case for the project. Second, building a guiding team of stakeholders was imperative to promote change. The cohesive group of medical, radiological and surgical oncologists, the Tumor Registrars, nurse navigators, and oncology staff members helped to guide the change. Selecting a champion for change, who is a well-respected individual within the group, helped to motivate the group. Third, creating a plan to integrate the SCP into standard care for oncology patients with measurable benchmarks led to: (a) improved patient care outcomes; (b) better informed and compliant patients; (c) better informed primary care physicians; and (d) increased patient satisfaction. This feedback loop reinforced the necessity of integrating the SCP into standard care. Fourth, it is important to communicate the vision with consistent messaging reiterating the elements of step three. Repetition of the message is important to sustain success. Fifth, empowering individuals to promote the integration of the SCP into standard care promoted action through removing barriers to implementation. Removal of barriers was important for the success of the project. Careful patient scheduling was key for oncology staff buy-in and to reduce stress within the organization related to this change. It was imperative that the scheduling of patients not conflict with the clinic flow. Sixth, create short-term wins by sharing successes. 
Outline the success of the pilot program with the team of stakeholders and the oncology ancillary staff. Share the reimbursement numbers with management and share patient stories of satisfaction. Seventh, consistently reinforce the integration of the SCP into standard care of oncology patients through completion of the project. Use key stakeholders, including Georgetown University Department of Professional Nursing Practice colleagues and key mentors to brainstorm and overcome challenges. Eighth, nourish the new change to sustain the change through reinforcement of the DNP Scholarly Project's short and long-term successes, and inform key staff members and stakeholders regarding project outcomes. Throughout the project, continually evaluate the program progress and make small adjustments as needed to maintain the success of the program.

Following the successful implementation, completion, and evaluation of the project, it will be imperative to integrate the new evidence-based practice into the oncology patient standard of care to promote continued accreditation of the Cancer Program. Transfer of the elements created to implement the project need to be clearly outlined for all team members. Periodic monitoring of the process of the implementation of the SCPs and TSs to the cancer patients will need to be built into the procedures of the oncology practice. Other members of the oncology team will need to understand the process to allow their active participation in SCP/TS to the oncology patients. In addition, innovative methods will need to be explored to streamline the process of development and delivery of the material to the patients, for the sustainability and cost effectiveness of the program.

\section{Research Question}

What is the effect of integration of SCPs into standard of care for adult stage I, II, and III breast cancer and colon cancer patients who have completed initial intent-to-cure treatment on 
the following outcomes: (1) participants' knowledge level regarding disease process; (2) satisfaction with delivery of health care at the DNP Scholarly Project setting; (3) HR-QOL; and (4) adherence to surveillance follow-up care and diagnostic testing? It is hypothesized that the integration of patient-specific SCPs into standard care for stage I, II, and III adult breast and colon cancer patients, who have completed their course of initial intent-to-cure treatment at the project clinical site, will increase patient knowledge regarding their disease, health promotion and disease prevention, improve patient satisfaction with delivery of healthcare and healthrelated quality of life, and increase patient adherence to surveillance follow-up care and diagnostic testing.

\section{Theoretical and Conceptual Frameworks}

Jean Watson's Theory of Caring Science is the theoretical framework for this DNP Scholarly Project. The ten carative factors of Watson's theory form a strong foundation for this project: embodiment of a humanistic-altruist value system; instilling faith-hope; fostering sensitivity to one's self and to others; support a helping-trusting relationship; allow for open expression of positive and negative feelings; conduct studies utilizing the systematic use of the scientific method; promote interpersonal teaching-learning; promote health, restore health and/or prevent illness; assist with the gratification of human needs, and understanding the person from his/her frame of reference. Donabedian's quality of care model will be used to outline the design phase of the project to evaluate the delivery of SCPs to improve patient outcomes of research interest. Donabedian's (1988) framework categories of structure, process, and outcome are used to guide the project design (Table 2). 
Table 2. Donabedian Model Elements within the DNP Scholarly Project Model.

\begin{tabular}{|c|c|c|}
\hline Structure & Process & Outcome \\
\hline $\begin{array}{l}\text { - Oncology practice } \\
\text { Breast and colon cancer patients } \\
\text { stage I, II, and III who have } \\
\text { completed initial intent-to-cure } \\
\text { cancer therapy } \\
\text { - Dedicated Oncology Staff } \\
\text { ○ Medical oncologist } \\
\text { O Nurse practitioner } \\
\text { O Tumor registrar staff } \\
\text { O Patient navigators } \\
\text { Resources } \\
\text { O Journey Forward SCP } \\
\text { O Patient education handouts }\end{array}$ & $\begin{array}{l}\text { - Integration of SCPs into } \\
\text { standard oncology care } \\
\text { - Outcome measures } \\
\text { ○ Patient satisfaction: PSQ-18 } \\
\circ \text { Health-related quality of life } \\
\text { (HRQOL): MOS-SF-36 } \\
\circ \text { Knowledge of diagnosis, } \\
\text { treatment, and surveillance } \\
\text { recommendations } \\
\circ \text { Adherence to recommended } \\
\text { follow-up visit and } \\
\text { surveillance exams }\end{array}$ & $\begin{array}{l}\text { - Improvement in patient } \\
\text { satisfaction, HRQOL, } \\
\text { knowledge of diagnosis, } \\
\text { treatment, and surveillance, and } \\
\text { adherence to recommended } \\
\text { follow-up visit and surveillance } \\
\text { exams } \\
\text { Compliance with the ACS CoC } \\
\text { mandated guidelines to maintain } \\
\text { accreditation at the study site } \\
\text { cancer care program }\end{array}$ \\
\hline
\end{tabular}

Adapted from Donabedian's Quality of Care Model, 1988 


\section{Definition of Terms}

Accreditation: recognition of an institution that demonstrates compliance with requirements and standards.

Adherence: the act of doing what is requested or recommended

Cancer survivor: an individual diagnosed with cancer from the time of discovery to the end of life.

Evidence-based practice: the integration of clinical expertise, patient values, and the use of current research in the decision making process for patient care.

Informed consent: the process that assures the research participant clearly comprehends the risks and benefits of participation in a research study

Institutional Review Board: the ethics committee that reviews and approves research studies involving human subjects

Integration: the process of uniting parts to make as one.

Intent-to-cure: the treatment of an individual with the intent to cure the disease.

Patient navigator: a person who guides a patient through the continuum of medical care Quality Improvement: a process to make changes that will lead to better patient outcomes Surveillance: the close monitoring of a cancer patient

Survivorship Care Plan: a coordinated plan for the cancer patient and their healthcare team. Thematic network analysis: a process used to extract basic and global themes from text to understand relationships and patterns.

Treatment summary: a detailed summary of a person's cancer treatment Tumor registrar: data information specialists that capture a complete history, diagnosis, treatment, and health status for cancer patients. 


\section{Chapter II}

\section{Review of the Literature}

A literature review was conducted to elucidate background information, previous reported challenges faced with integrating the SCP into standard care, and specific SCP-related patient outcomes. Electronic databases searched included the Cumulative Index to Nursing and Allied Health Literature (CINAHL), the Excerpta Medica Database (EMBASE), and MEDLINE/PubMed. Search terms were combined as follows: survivorship care plan* OR treatment summar* OR discharge summar*, AND cancer* OR neoplasm* OR malignan* OR oncolog*, AND implementation. Inclusion criteria included: a) publication years 2005 through 2015; b) English language; c) adult cancer patients $\leq 18$ years of age who had completed intentto-cure treatment; d) research studies related to adult cancer survivors; e) research studies examining outcomes of integration of SCPs into standard care. Exclusion criteria included: a) pediatric cancer treatment; b) expert opinion articles; and c) case studies. EMBASE, MEDLINE/PubMed, and CINAHL searches yielded 15, 22, and 23 articles, respectively. Duplicate studies were omitted. An additional manual search was conducted for references within the identified articles. A total of ten abstracts met inclusion criteria and the publications were reviewed. Seven research studies, two integrative reviews, and one systematic literature review were systematically reviewed.

\section{Critique and Synthesis of the Evidence}

Scientific rigor of the individual published research studies, which taken together comprise a scientific body of evidence, was graded following the Agency for Healthcare Research and Quality (AHRQ) (AHRQ, 2002) guidelines. These AHRQ guidelines use three domains to evaluate the evidence: a) quality-the extent to which the researchers minimized 
selection and measurement bias (internal validity); b) quantity-the number of studies that evaluated the clinical issue, sample size or power, and extent of treatment effect; and c) consistency-determining if the different studies report similar findings.

Three integrative/systemic literature reviews were included in the review. Birken, et al. (2015) reviewed 16 publications promoting SCP guidelines using the Appraisal of Guidelines for Research and Evaluation (AGREE II) instrument. Eleven of 16 publications presented SCP guidelines which were scored low on the AGREE II instrument; only five of the SCP guidelines scored $>50 \%$ on the AGREE II instrument. Birkin, et al. (2015) did not find that any of the SCP guidelines strongly supported the use of the SCP into patient care. Mayer, Birken, Check, \& Chen (2014) and Taylor \& Monterosso (2015) conducted integrative literature reviews using the Preferred Reporting Items for Systematic Review and Meta-Analysis (PRISMA) search strategy. Studies were examined regarding use, content, and outcomes of SCPs (Mayer, et al. 2014) and to determine the usefulness of the delivery of SCPs and TSs in the hematological cancer setting (Talyor \& Monterosso, 2015). Taylor \& Monterosso identified four studies outlining the benefits, limitations, and outcomes of the SCPs delivery to patients with hematological cancers. Mayer et al. (2014) summarized 42 articles identifying the body of evidence describing SCP use, content, and outcomes for adult cancer survivors reporting that patients appreciated the SCP information. Mayer et al. (2014) identified large gaps in content of the SCP, and stated that most studies were observational studies with a sample of white, female, breast cancer survivors. The authors of both reviews concluded that the delivery of the SCPs to cancer patients is routinely lacking. There is insufficient data showing improvements in patient outcomes with the delivery of SCPs to adult cancer patients, and thus, additional rigorous research studies are needed to validate improvement in patient outcomes following receipt of a SCP (Mayer et al. and Taylor \& 
Monterosso). Birken et al. (2015) stressed that SCP guidelines need to undergo evaluation through use of validated tools such as the AGREE II prior to adopting the SCP guideline into clinical practice.

The literature review identified only one randomized-controlled clinical trial. Grunfeld et al. (2011) enrolled 408 female subjects ( $X=61$ years of age), who had completed primary adjuvant treatment for breast cancer stage I to III at nine tertiary oncology practices in Canada. Subjects were randomized to two groups: a) intervention group: received the SCP; and control group: did not receive the SCP. The sample was stratified into $<24$ months and $\geq 24$ months following diagnosis. All subjects were transferred to their primary care provider following informed consent. The researchers used the Impact of Events Scale (IES), Profile of Mood States (POMS), Short Form-36 (SF-36) to measure health-related quality of life (HRQOL), Medical Outcomes Study-Patient Satisfaction Questionnaire (MOS-PSQ), and continuity/coordination of care tool (CCCQ) to evaluate the primary outcome of cancer-related psychological distress, and secondary outcomes of general psychological distress, HRQOL, patient satisfaction, and continuity of care at baseline, and at 3,6,12,18, and 24 months. Socio-economic and ethnicity data were not collected. Preliminary 12-month data did not support the researchers' hypothesis that the delivery of a SCP would reduce cancer-related psychological distress over time. The sample size did not allow statistically significant results because 100 subjects per each of the four strata were needed to show statistical significance. Data analysis showed 180 subjects in the control group ( 80 subjects $<24$ months and $100 \geq 24$ months from diagnosis) and 165 subjects in the intervention group ( 74 subjects $<24$ months and 91 subjects $\geq 24$ months from diagnosis) at the 12-month follow-up analysis. This small sample of highly educated breast cancer patients did not allow generalizability beyond this sample. 
Palmer et al. (2015) conducted a quasi-experimental study to examine the effect of the SCP on patient satisfaction, patient use of SCP information, and HRQOL. The sample $(\mathrm{N}=193)$ of stage 0 , I, II, and III female breast cancer patients, ranging in age from 25-80 years, primarily white $(90 \%)$, with black representation (10\%), was recruited at seven National Cancer Institutedesignated Comprehensive Cancer Centers. Patients were excluded if they were unable to read the informed consent. Participants had been diagnosed 3-240 months from study enrollment. One hundred and thirty-nine subjects received SCPs and completed baseline and 3-month follow-up questionnaires including MOS-SF-12 evaluating HRQOL, an investigator-created 16 item survey evaluating subjects' use of SCP information, and investigator-created assessment tool evaluating patient satisfaction and use of the SCP. Palmer et al. (2015) reported that delivery of the SCP to breast cancer patients contributed to increased patient satisfaction, perceived survivorship knowledge, and use of educational materials provided within the SCP. Subjects who were diagnosed within 24 months of the delivery of the SCP were more likely to use the educational information to make more appropriate life-style decisions. Limitations of this study included the single follow-up time period, use of investigator-created research instruments that may have introduced investigator bias, and the sample consisting of primarily white, welleducated, mid-upper socioeconomic class participants. The quasi-experimental study design is useful in populations within clinical practice because it does not require randomization or a control group and thus, is useful for DNP quality improvement projects (Rouen, 2014). The authors suggest further study with randomized controlled clinical trials to validate the results. A descriptive study by Dulko et al. (2013) assessed 55 health care providers' (oncology nurses and advanced practice providers, oncologists and primary care providers) perceptions of the benefits, challenges, and barriers to implementation of the SCP and 58 cancer patients' (48 
stage I-III breast cancer and 10 stage II-IV colon cancer) perceptions of the SCP visit at two academic medical centers in Vermont. Eligibility criteria included completion of intent-to-cure treatment within 12 months before or during the study period. Advanced practice providers (APPs) developed and delivered the SCP to the participants. Seventy-eight of $89(87.7 \%)$ eligible patients agreed to participate in the study. Fifty-eight of 78 (74.4\%) participants completed the telephone survey at 2 months following the SCP delivery; 20 participants either refused to complete the telephone survey or could not be contacted. Thirty-nine of the 55 primary care providers (PCPs) (70.9\%) completed written surveys. The 16 PCPs who did not return the survey were contacted several times in an unsuccessful attempt to return the questionnaire. Descriptive statistics were used to analyze the data. The mean time to create each SCP was 53.9 minutes and the mean time to deliver the SCP was 59.7 minutes. Participants reported that the SCP information was useful, especially when received within six months following cancer diagnosis. All participants stated that APPs should develop the SCP and deliver it to patients following their cancer treatment. The PCPs reported that they had insufficient knowledge regarding cancer survivor issues to provide competent cancer survivorship follow-up care. A model of shared-care was suggested by the authors to transition patients from the oncology setting to the PCP setting for follow-up care. The main limitation to this study was the small sample size. Results warrant further research using larger sample sizes.

Blanch-Hartigan, et al. (2014) evaluated the self-reported frequency of the delivery of SCPs, recommendations of follow-up care, and providers' responsibilities to breast and colon cancer survivors, and PCPs' perceptions of their responsibilities for caring for cancer survivors and discussing the SCP with their patients. Data were extrapolated from the Survey of Physicians' Attitudes Regarding the Care of Cancer Survivors (SPARCCS), a national survey 
that was mailed to 1130 oncologists and 1072 PCPs in 2009. Eligible physicians were identified through the American Medical Association's master membership file. Physicians were stratified by specialty, race, age, census region, and metropolitan area. PCPs were excluded if they had never cared for a breast or colon cancer patient. Four outcome variables were measured: a) the oncologist's provision of the SCP to patients; b) the oncologist's discussion of the recommendation and provider responsibility with patients; c) PCPs discussion of SCP with patients; and d) oncologist's provision and discussion of the SCP elements and recommendation to patients. Data were analyzed using three multiple logistic regression models because of the multiple levels of influence of the social ecological influences: physician factors; difficulties encountered in care; care coordination factors; and practice environmental factors. The results showed that oncologists were younger, and had a higher likelihood of being Asian and male than PCPs. Overall, less than $10 \%$ of oncologists reported providing SCPs to their patients and less than 5\% reported providing the SCP and having a discussion with their patients regarding surveillance recommendations and follow-up care. Interestingly, 21\% of PCPs outlined recommendations for follow-up cancer care with their patients and 34\% of PCPs discussed which practitioner would follow them for their cancer care. Blanch-Hartigan et al. (2014) reported that this was the first US survey study to analyze physician-predictors for provision of SCP. Although the large nationally representative sample strengthened the study, study results were limited because the researchers were unable to interpret correlations with the lack of oncologist's provision of SCP and discussion of follow-up care recommendations with cancer survivors. The researchers recommend further interventional studies to test the hypothesis that improved care coordination and oncologist survivorship training will lead to survivorship 
adherence with follow-up care recommendations leading to improved patient QOL and extended survival time.

Three qualitative studies were included in the review of the evidence. Ashing-Giwa et al. (2013) utilized a community-based participatory research (CBPR) framework to examine the African-American breast cancer survivor's understanding of and access to SCPs and their responsiveness to the cultural needs of African-Americans. Twenty-eight members of the African-American Cancer Coalition were recruited to participate in three consensus meetings. Twenty-five of the African-American participants, ranging in age from 32- 79 years, were stage 0, I, II, and III breast cancer survivors. Thirty-six percent of the survivors were less than 5 years from their initial breast cancer diagnosis. The remaining three participants were healthcare advocates. Participants gave written informed consent and participated in three consensus sessions, two weeks apart. Participants were videotaped during the first and second meetings. The time between each session allowed the researchers to analyze the video recordings and numerous notes, integrating the participants' feedback, ascertaining subject awareness of the SCP and to gain an understanding of the cultural needs of the African-American breast cancer survivor for future development of a more patient-centered SCP. Data were analyzed using a deductive approach, involving two independent members of the research team. Although not specifically mentioned, this study used an ethnography/video-assisted ethnography study design. The data were organized into matrices, representative of the domains outlined in the American Society of Clinical Oncology (ASCO) Cancer SCP template. The results of this qualitative study revealed that only one of the participants had received a SCP from her oncologist. Participants reported multiple co-morbidities that may contribute to an increased risk of disease recurrence. The researchers concluded that SCPs need to be more personalized to address the individual's 
underlying clinical, behavioral, and psychosocial risk factors for recurrence of disease. Using input from African-American cancer survivors is important to develop patient tailored SCPs. Limitations to the study included the data collection procedure in a group setting because the authors agreed that group dynamics may have influenced the data collected. More extroverted and more verbal participants' may have overshadowed more reserved, quieter participants. Medical professionals' input during the consensus meetings would be beneficial to clarify any negative misperceptions regarding SCP implementation. Mixed methods using both qualitative and quantitative designs would be useful to examine the elements of the SCP as they relate to cultural sensitivity and health care disparities.

Hahn \& Ganz (2011) described the development, use, and implementation of SCPs at four healthcare institutions in Los Angeles, CA. This qualitative study utilized a semi-structured interview format to query oncology nurse specialists, nurse practitioners, social workers and administrative personnel about their cancer survivorship programs. The four healthcare institutions included an academic center, a community hospital, a county hospital, and a primarycare medical group. Study results showed that each clinical setting developed unique approaches to the development and delivery of the SCP. Also reported were variations of patient populations, cancer survivorship program staff members, and differences in the delivery of the SCP to the patient. The individual SCPs differed from institution to institution. The SCP was completed by a variety of individuals at each institution: 1) a team including an oncologist, nurse practitioner and psychologist; 2) a dedicated survivorship nurse practitioner; 3) a contracted oncology group of physicians and staff; and 4) the patient with assistance from an oncology nurse. All of the SCPs included identical treatment history components. Three of the four centers used the ASCO recommended surveillance recommendations. The data were presented 
in a narrative format and provided background information for development of a survivorship program. This study lacks scientific rigor because data regarding the effectiveness of the different styles of SCP development, use, and implementation was not presented. Further research is needed to evaluate the validity and reliability of the diverse styles of adopted survivorship care programs and SCP development and implementation to cancer patients across the US.

Haq et al. (2013) studied the informational needs of breast cancer patients, family physicians, and oncology health care professionals (OHCPs) to develop a SCP based upon the identified needs in a qualitative, single-center pilot study. Twenty-one stage I, II and III breast cancer patients, eight family practitioners, and six oncology health care providers were recruited from a tertiary-care, academic teaching hospital in Toronto, Canada between March 2009 and November 2010. All participants consented be take part in focus groups and to be interviewed. English language proficiency was a requisite. Qualitative data were collected before and after the development of a SCP. Phase 1 of the study investigated the informational needs of patients and family practitioners, querying participants on patient needs, knowledge gaps, preferences to transition care to family provider and preferred formats for receipt of information. OHCPs answered questions about their perceptions of the unique needs of patients and family practitioners. In Phase 2, a pilot, linked, web-based SCP (one for patient and one for family practitioner) was developed based upon Phase 1 results. Each website focused on the specific needs of the patients and the family practitioners. The patient website focused on informational needs with links to support groups. The family practitioner website included a link to Canadian clinical practice guidelines, specific to breast cancer survivors' long-term side effects of treatment, management and follow-up surveillance guidelines. In Phase 3 of the study, an 
additional 26 participants (18 breast cancer patients, five family practitioners and three oncology health care providers) evaluated the components of the SCP via focus groups or in-depth interviews. Topics included ease of navigating the website, strength of addressing the content of informational needs and gaps in knowledge, suggestions for improvement, and understanding what works and what does not work within the web-based design. In both Phase 1 and Phase 3, data were analyzed in conjunction with data collection using an iterative and emergent design. Two experienced qualitative research analysts transcribed the videotapes and interviews verbatim, coding the information into emerging themes. Cross coding was utilized to recognize inter-relatedness of the themes. Analytic rigor was ensured by the use of triangulation and comparisons of coding between the analysts. This study was a well-designed qualitative research study outlining an attempt to personalize survivorship care plans to meet individual patient needs. This study captured features of the lived experiences of cancer patients and found that SCPs can be personalized to individual breast cancer survivors. Although not described in the article, this study utilized a video-assisted ethnography designed approach. This study also utilized the Internet to develop SCPs with patient involvement. However, until the use of the Internet becomes universal, this method of patient involvement will not be feasible in underserved, low socioeconomic populations. Limitations to this study were the small sample size, especially of the family practitioners.

\section{Rationale for the Project}

The rationale for this DNP scholarly project was two-fold. First and foremost, to integrate the SCPs into standard care to meet the ACS CoC compliance standards for the Western US hospital's as a cancer center. Additionally, the validation for this study is derived from the synthesis of the evidence base for use and evaluation of SCPs within the oncology 
setting. The studies recommended further research to better understand: a) the subject's desire for the knowledge (Taylor \& Monterosso, 2015); b) methods to improve the quality of the guidelines (Birken et al. 2015); c) comparison of patient outcomes between groups who receive or who do not receive SCPs (Blanch-Hartigan et al., 2014; Hahn and Ganz, 2011; Haq et al., 2013; Mayer et al., 2015; Palmer et al., 2015); d) whether patients with cancers other than breast cancer have improved outcomes following delivery of SCPs (Grunfeld et al., 2011); e) how nurse practitioner's role may reduce barriers to implementation of the SCP and the outcome of improved cancer survivorship care (Dulko et al., 2013); f) cost-effectiveness of SCPs (Palmer et al., 2015); g) the quality and content of the SCP and the quality and content of the oncologist's and PCP's survivorship care discussions (Blanch-Hartigan et al., 2014); and h) the impact of "patient-centered, holistic personalized survivorship care plan development on patient outcomes (Ashing-Giwa et al., 2013; Haq et al., 2013).

Although inconsistent results were observed among the studies reviewed, a common theme emerged showing gaps in the provision of SCPs to cancer patients at the completion of their intention-to-cure treatment and a lack of consistency in the delivery of SCPs between the various oncology practices. Study procedures were not always adequately described to allow study replication. Some of the studies showed positive outcomes with the SCPs and some of the studies reported an acceptance of the null hypothesis with the implementation of the SCP compared to the control group. There was a paucity of diverse ethnic and socio-economic representation in the samples of all studies. The paucity of evidence to support the inclusion of SCPs into standard oncology patient care warrants further research to build the evidence base for practice (Melnyk, Morrison-Beedy, \& Cole, 2015). 


\section{Chapter III}

\section{Methods}

\section{Design}

The DNP scholarly project used a quasi-experimental, pretest-post-test design. Inclusion criteria included: a) $\geq 18$ years of age; b) stage I, II, II breast cancer or colon cancer patients who had completed initial intent-to-cure treatment, including patients on maintenance therapy or adjuvant hormonal therapy, at the medical oncology clinic project setting; and c) able to give written informed consent. Exclusion Criteria: a) pediatric oncology patients; and b) unable to give written informed consent.

\section{Sampling Plan}

A purposive sample was used to recruit eligible patients who had completed their initial intent-to-cure treatment during the scheduled patient visit in the Medical Oncology Clinic.

\section{Setting}

This DNP scholarly project was conducted in a hospital-based Medical Oncology Clinic located within a county hospital in the Western US. Professional staff working in the Medical Oncology Clinic included two physicians, one of whom is the acting Medical Director of the Medical Oncology Clinic, and two oncology nurse practitioners. The Medical Oncology Clinic had a significant unmet need regarding providing SCPs to patients after completion of initial intent-to-cure cancer treatment. This Medical Oncology Clinic serves as a primary gatekeeper for the majority of the cancer patients who receive intent-to-cure cancer treatment within this Western US county. Clinic providers care for 45-50 cancer patients per day. Patient demographics include adult, multi-ethnic cancer patients primarily living within the county, which is one of the lowest socioeconomic counties in the US. The project population seen at the 
Medical Oncology Clinic is racially, culturally, socio-economically, and educationally diverse. A high percentage of Hispanic patients who have not completed high school and primarily speak Spanish are seen in the medical oncology.

\section{Study Instruments}

All study instruments and the informed consent document were provided to the participant in either English or Spanish, as appropriate. A large proportion (60\%) of the community served by the Medical Oncology Clinic are non-English speaking Hispanics. Thus, to assure a representative sample of Hispanics in this study, the translation of all study instruments from English to Spanish was certified, and received IRB approval. Study questionnaires and case report forms were identified with a three-digit study number using an honest broker approach. Specific study instruments included the following:

Sociodemographic Data Form (SDF). The investigator-created SDF captured data to characterize the sample and includes date of birth, gender, race, ethnicity, education level, current employment status, and household income variables. This data were abstracted from both the patient electronic medical record or from the patient at the baseline visit.

Clinical Data Form I (CDFI). The investigator-created CDFI captured clinical data abstracted from the participant's electronic medical record including cancer diagnosis and stage, initial intent-to-treat treatment type, and co-morbidities.

Clinical Data Form II (CDFII). The investigator-created CDF II captured clinical data abstracted from the participant's electronic medical record including cancer progression from baseline, and new co-morbidities from baseline (e.g. new primary cancer).

Medical Outcomes Study Form-36 (MOS-SF-36). The MOS-SF-36 was used to measure HRQOL. The MOS-SF-36 measures eight health domains: 1) physical functioning; 2) role 
limitations due to physical problems; 3) bodily pain; 4) general health perceptions; 5) vitality; 6) social functioning; 7) role limitations due to emotional problems; and 8) mental health (Ware \& Sherbourne). This instrument has demonstrated validity and reliability (Ware and Sherbourne, 1992). Test-retest reproducibility and internal consistency data was reported by Bousquet (1994). The MOS-SF-36 has been used in study populations 14 years of age and older (Ware \& Sherbourne, 1992). The MOS-SF-36 takes approximately ten minutes to complete.

Patient Satisfaction Questionnaire Short Form-PSQ-18. The 18 item PSQ-18 assesses patient satisfaction in seven domains of medical care: 1) general satisfaction; 2) technical quality; 3) interpersonal manner; 4) communication; 5) financial aspects; 6) time spent with practitioner; and 7) accessibility and convenience (Marshall \& Hayes). The PSQ-18 has been used by McDowell, Occhipinti, Ferguson, Dunn, \& Chambers (2010) to evaluate 439 cancer patients' satisfaction with health care, and has demonstrated appropriate reliability. The PSQ-18 takes approximately five minutes to complete.

Patient Knowledge of Disease Questionnaire (PKDQ). The investigator-created 10-item PKDQ captured the participants' knowledge of cancer diagnosis, cancer stage, completed cancer treatment, and rationale for follow-up tests and surveillance. The faculty mentor reviewed this form for content validity. The PKDQ takes approximately five minutes to complete.

Open-Ended Evaluation Questionnaire (OEEQ). Participants will complete the OEEQ questions 1 and 2 at the follow-up visit. The OEEQ questions were: a) Please describe your experience with the delivery of survivorship care plan; b) Since receiving the information in the survivorship care plan, have you made changes to your health? If yes, please describe these changes. 


\section{Survivorship Care Plan (SCP) Intervention}

The SCP was developed by the doctoral student in collaboration with clinical site's Tumor Registry personnel, and the oncology patient navigator. Each participant-specific SCP required 45-60 minutes to create. The SCP includes the following components: a) patient identifiers; b) members of the care team; c) cancer diagnosis specifics; d) treatment plan and summary; and e) follow-up care and recommendations

The Journey Forward SCP builder computer software program was created by Anthem, Inc., the University of California, Los Angeles (UCLA) Jonsson Comprehensive Cancer Center, the National Coalition for Cancer Survivorship, and Genentech, Inc. based on the recommendations from the 2005 IOM report, "From Cancer Patient to Cancer Survivor: Lost in Transition" (Hausman, Ganz, Sellers \& Rosenquist, 2011). The goal of the Journey Forward SCP is to summarize and communicate the patient's cancer treatment, including potential risks and known complications of the treatment, outline known and potential late and long-term effects of the cancer treatment, detail the recommended surveillance guidelines for follow-up and diagnostic testing, communicate to the patient and primary care providers recommendations to promote a healthy life-style to prevent disease recurrence and decrease the risk of acquiring other co-morbidities (Hausman, et al.). This computer software program was chosen to create the SCP intervention because of compliance with all requirements set by ASCO and the IOM, no computer upload cost, and ease of implementation and computer use.

\section{Procedures}

The study received institutional review board approval (Georgetown University Institutional Review Board and the local hospital Institutional Review Board) before data collection began. 
Participant Recruitment. All eligible patients in the doctoral student's clinical practice received the SCP as part of standard care. Only patients who chose to participate in this scholarly project gave written informed consent and completed the project instruments pre- and post-SCP intervention and at the scheduled Medical Oncology Clinic follow-up visit. Eligible patients were identified by the medical oncologists or the nurse practitioners working in the Medical Oncology Clinic at completion of their initial intent-to-cure treatment with surgery, chemotherapy, and/or radiation therapy at the time of their scheduled SCP visit. All eligible patients were invited to participate in the project by the medical, surgical and/or radiation oncology providers at the county hospital. The patients were referred for a SCP visit by the provider and scheduled for the visit.

The IRB-approved informed consent document, which contains study rationale, study procedures, potential risks and benefits of study participation, assurance that the patient may leave the study at any time he/she wishes, and the potential risk and benefits, was reviewed by the DNP scholar with the patient, read by the patient, and reviewed again with the patient for any additional questions. Written informed consent was obtained from all patients who agreed to participate in the scholarly project and administered per International Conference on Harmonization (ICH) guidelines. Potential study participants were consented in a quiet exam room, within the Medical Oncology Clinic.

SCP Intervention and Questionnaires' Administration. Each participant had two visits as part of the study.

SCP initial visit. A Medical Oncology Clinic nurse practitioner performed the initial SCP clinic visit. Before the SCP intervention, the NP administered the following project questionnaires in the following standardized order: a) Sociodemographic Data Form (SDF); b) 
Medical Outcomes Study Form-36 (MOS-SF-36); c) Patient Satisfaction Questionnaire Short Form (PSQ-18); and d) Patient Knowledge of Disease Questionnaire (PKDQ). The hard copy questionnaires were completed with a black ink pen. Following the completion of the questionnaires, the nurse practitioner delivered the SCP intervention, and provided the patient with a hard copy of their tailor-made SCP. The patient's primary care provider also received a copy of the SCP. The delivery of the SCP took approximately 45 to 60 minutes. After the SCP intervention was completed, the nurse practitioner administered the (PKDQ)..

Follow-up visit. At the scheduled follow-up visit, before any clinical procedures or patient education associated with the visit were conducted with the patient, the nurse practitioner administered the following questionnaires in the following standardized order: a) MOS-SF-36; b) PSQ-18; c) PKDQ; d) and OEEQ. The CDFII was also completed by the nurse practitioner.

\section{Data Analysis}

The data analysis plan was created in consultation with the study statistician to describe the sample, integration of the SCP into standard patient care in the Medical Oncology Clinic, and to answer the research question. Data analyses were conducted using Microsoft ${ }^{\circledR}$ Excel ${ }^{\circledR}$ and IBM ${ }^{\circledR}$ SPSS ${ }^{\circledR}$ software. A variety of descriptive statistics was computed on the sample to furnish a clinical and demographic profile of characteristics of all participants. These statistics include measures of frequency and percentage distributions for categorical variables, and central tendency and dispersion, which included means, standard deviations, skewness, and kurtosis.

In order to assess the integration of SCP implementation into standard care for breast and colon cancer patients in the medical oncology clinic, the percentage of cases in which SCP was implemented was calculated. 
Inferential statistics were used to assess the effect of the SCP intervention on participants' knowledge level regarding disease process, satisfaction with delivery of health care, and HRQOL. Mean scores on the Patient Knowledge of Disease Questionnaire (PKD) were compared at three times: pre and post the SCP intervention; and at the follow-up clinic visit, using repeated measures ANOVA. Because knowledge scores were skewed at post and followup, a Friedman test (the nonparametric equivalent of repeated measures ANOVA) was also run verify results from ANOVA. Paired samples $t$ tests were used to compare scores on the subscales of the MOS-SF-36, which measures health related quality of life, and the subscales of the PSQ-SF-18, which measures satisfaction with health care delivery, pre SCP intervention and at the follow-up clinic visit.

To access effect of the SCP on adherence to the Medical Oncology Clinic follow-up visit and to the individual patient surveillance plan per National Comprehensive Cancer Network guidelines and medical orders, the percentage of participants who adhered to the follow-up and their individual surveillance plan of care was calculated.

Participant responses from the Open-Ended Evaluation Questionnaire (OEEQ) were classified utilizing a thematic network analysis as described by Terry (2105, pg. 205-206). The steps to this process include 1) reducing the data, 2) identifying the themes, 3) arranging the themes into similar groups, 4) describing the networks, 5) summarizing the main themes and patterns characterizing the network, and 6) compiling and describing the global themes that emerged.

\section{Data Management}

Completed hard copy project questionnaires, and signed informed consent documents were transported after data collection in the Medical Oncology Clinic to a locked file cabinet in 
the researcher's work office. The researcher maintained participant confidentiality through the process of separating participant names from their identification numbers and their questionnaire responses. One form was maintained recording the participant names, the participant study number, the date of participant accrual, and the date of data collection.

The project codebook contained all information regarding data coding to insure that raw data were entered correctly into the study computer. Missing data was coded per project coding guidelines as presented in the project codebook. The codebook will be maintained in a locked file in the researcher's work office. The researcher entered de-identified study data entered into the study Microsoft ${ }^{\circledR}$ Excel ${ }^{\circledR}$ file. Double data entry was used to assure data accuracy. Data access was limited to the researcher and the clinical on-site mentor, the Director of the Medical Oncology Clinic. 


\section{Chapter IV}

\section{Results}

\section{Characteristics of the Sample}

The sample $(\mathrm{N}=42)$ was primarily female $(85.7 \%)$, middle-aged $(\bar{\chi} 55.26$ yrs. $)$ white (97.6\%), Hispanic/Latino (85.7\%), unemployed or retired (76.2\%), and a non-high school graduate (61.9\%), with an annual household income of less than $\$ 20,000$ (76.2\%) (Table 3;

Figures 1 and 2).

Table 3. Participant Demographics. $(\mathrm{N}=42)$

\section{Characteristic}

Age, years

Mean

SD

Range

Gender

Male

Female

Race

American Indian

Asian

Black

Native Hawaiian

White

Ethnicity

Non-Hispanic/Latino

Hispanic/Latino

Educational level

8th grade or less

Some High School

High School Graduate

Some College

College Graduate

Employment Status

Retired

Unemployed

Part-time employee

Full-time employee

Annual Household

Income(US dollars)

$<\$ 20,000$
$\$ 20-50,000$
$\$ 51-100,000$
$>\$ 100,000$

$n \quad(\%)$

55.26

9.48

30-70

6

36

14.3

85.7

$\begin{array}{ll}0 & 0.0\end{array}$

0

1

0.0

2.4

0.0

97.6

41

6

36

14.3 85.7

$14 \quad 33.3$

$12 \quad 28.6$

$\begin{array}{ll}7 & 16.7\end{array}$

$\begin{array}{ll}7 & 16.7\end{array}$

$\begin{array}{ll}7 & 4.7\end{array}$

8

24

7

3

3

19.1

57.1

16.7

7.1

$\begin{array}{lr}32 & 76.2 \\ 9 & 21.4 \\ 1 & 2.4 \\ 0 & 0.0\end{array}$

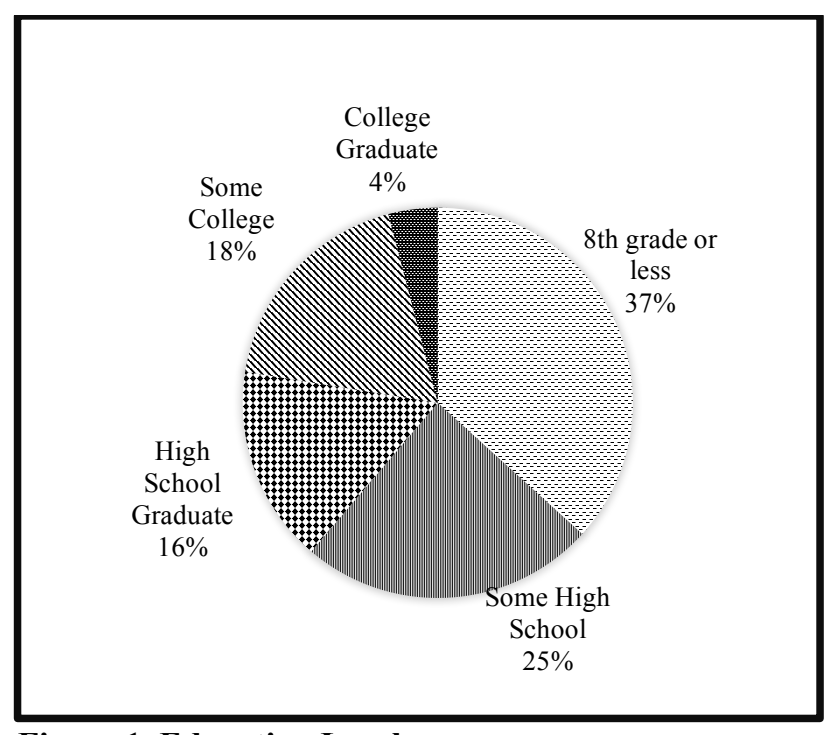

Figure 1. Education Level

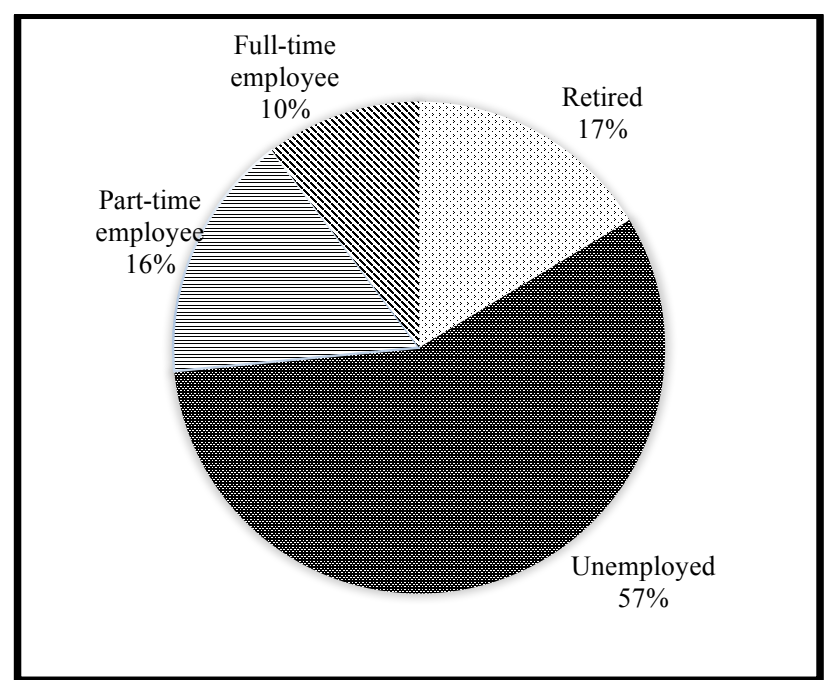

Figure 2. Employment Status 
Disease characteristics of the participants at baseline are presented in Table 4. The sample was comprised of 35 (83.3\%) stage I, II, and III breast cancer patients $(37.1 \%, 28.6 \%$, $34.3 \%)$, respectively, and 7 (16.7\%) stage II and III colorectal cancer patients $(28.6 \%, 71.4 \%)$, respectively (Table 4). More than 50\% of the participants (57.1\%) had their cancer diagnosed less than 24 months prior to enrollment. Half of the intent-to-cure cancer treatment included combined surgery, radiation, and chemotherapy for breast and colorectal cancers combined. A majority of the participants self-reported one or more co-morbidities (73.8\%) with $28 \%$ of the participants self-reporting 3 or more co-morbidities.

Table 4. Clinical Characteristics of the Sample. $(\mathrm{N}=42)$

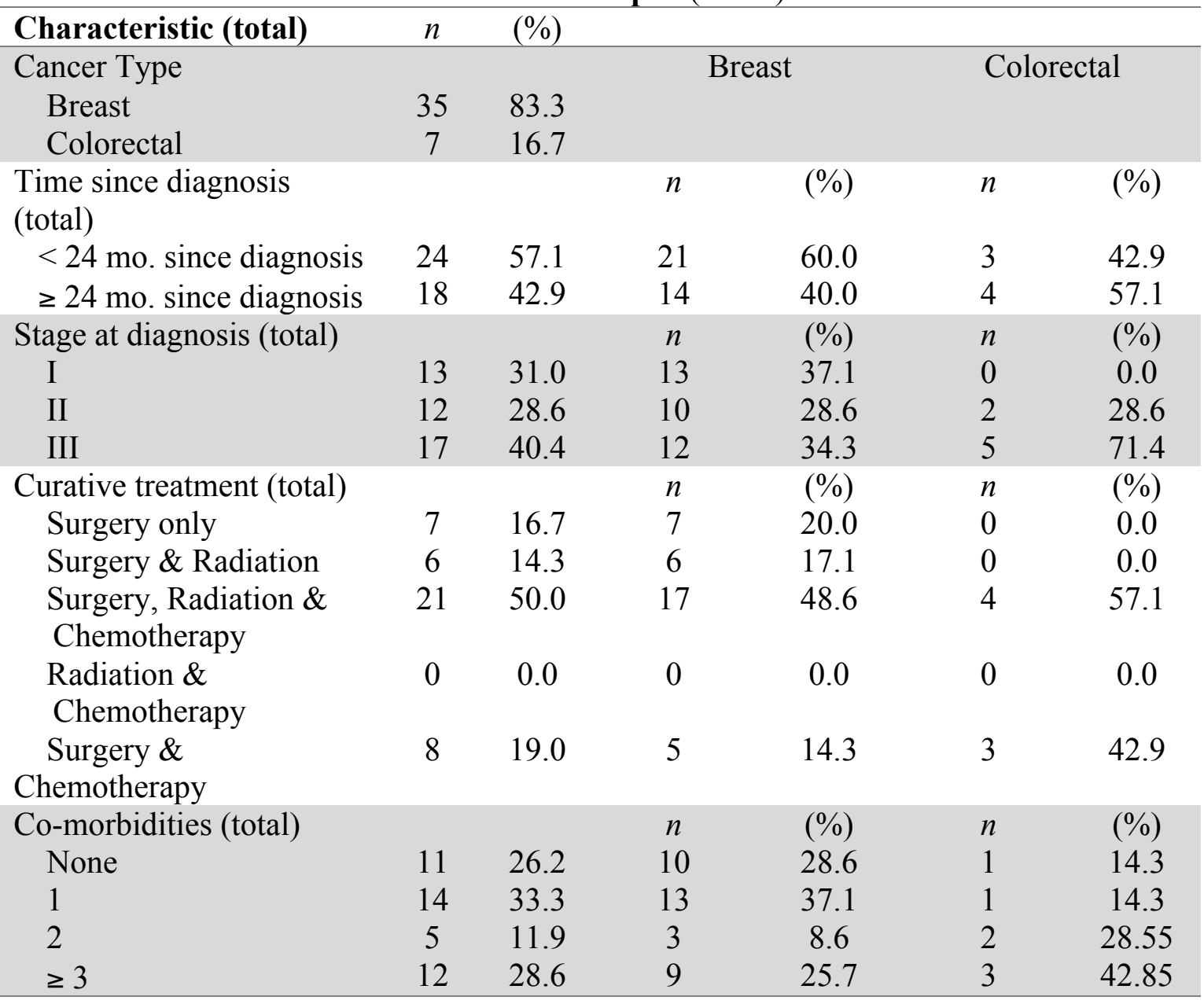




\section{Primary Aim}

The primary aim of this DNP scholarly project of integrating the SCP into standard care for adult stage I, II, and III breast and colon cancer patients after initial cancer treatment at the clinical site was accomplished. The SCP was administered to each participant by the DNP student. The time needed to implement the SCP was 45 minutes to 60 minutes/participant.

\section{Secondary Aims}

Secondary aims were to examine the effect of SCPs on participants' knowledge base regarding their cancer, health promotion and disease prevention, satisfaction with delivery of health care, health-related quality of life (HRQOL), and adherence to follow-up visits and surveillance testing. Completion of all follow-up questionnaires was missed for one subject.

Knowledge of Disease Questionnaire. Tables 5 and 6 present the participants' knowledge of disease outcome data. Statistically significant differences were seen (repeated measures ANOVA) in the percentage correct on the Knowledge of Disease Questionnaire among all three time points. Because knowledge scores at post intervention and follow-up were significantly skewed, a nonparametric Friedman's test was also run to test for significant differences across the three time periods. The results from the Friedman's test were consistent with the repeated measures ANOVA results, indicating a significant difference in knowledge across the time periods. ANOVA has the advantage of allowing pair-wise comparisons to determine which time periods differed for the others. ANOVA results are reported here, because of the equivalence of results and the availability of pair-wise post hoc comparisons. Although there was a decrease in correct answers from post-SCP intervention to follow-up study visit, follow-up visit scores remained statistically significantly higher than at pre-intervention time point. 
Table 5. Comparison of PKDQ Percentage Correct from Pre-to Post- SCP Intervention to Followup Visit. $(\mathrm{N}=41)$

\begin{tabular}{|c|c|c|c|c|}
\hline \multicolumn{5}{|c|}{ Percent Correct } \\
\hline & $\bar{\chi}$ & $(S D)$ & $F$ & $p$ \\
\hline Pre SCP & 69.8 & 16.5 & 46.618 & $<.001$ \\
\hline Post SCP & 93.3 & 10.0 & & \\
\hline Follow-up Visit & 87.6 & 13.7 & & \\
\hline
\end{tabular}

Seventy-nine percent of the participants correctly identified their cancer stage prior to the SCP intervention. Post-intervention, $100 \%$ of the participants correctly identified their stage of cancer. At the follow-up visit, $90.2 \%$ of the participants correctly identified their cancer stage.

Post SCP intervention, there was an increase in correct answers to all questions on the Knowledge Questionnaire (Table 6). The greatest increase in knowledge following the SCP intervention was the verification from the participants of having an understanding of symptoms of recurrence, followed by knowing who to call when there is a concern of recurrence, knowledge of follow-up guidelines, and support groups in the community. A majority of participants acknowledged that diet, exercise, smoking cessation and limiting alcohol intake to 12 drinks per week help to reduce the risk of cancer recurrence across all time points.

Table 6. PKDQ Correct Answers Pre, Post and at Follow-up (F/U). (N=42)

\begin{tabular}{|c|c|c|c|}
\hline & PRE & POST & $\mathrm{F} / \mathrm{U}(\mathrm{N}=41)$ \\
\hline What is your cancer stage? & $78.6 \%$ & $100 \%$ & $90.2 \%$ \\
\hline $\begin{array}{l}\text { How often do you need to have a follow-up visit with your } \\
\text { oncologist? }\end{array}$ & $71.4 \%$ & $88.1 \%$ & $92.7 \%$ \\
\hline $\begin{array}{l}\text { How often do you need to have a follow-up } \\
\text { mammogram/colonoscopy? }\end{array}$ & $61.9 \%$ & $88.1 \%$ & $87.8 \%$ \\
\hline $\begin{array}{l}\text { Do you believe that diet and exercise will help reduce the risk of } \\
\text { cancer recurrence? }\end{array}$ & $92.9 \%$ & $100 \%$ & $95.1 \%$ \\
\hline $\begin{array}{l}\text { Do you believe that stopping smoking will reduce the risk of cancer } \\
\text { recurrence? }\end{array}$ & $95.2 \%$ & $97.6 \%$ & $97.6 \%$ \\
\hline $\begin{array}{l}\text { Do you think that reducing alcohol consumption to } 1-2 \text { drinks per } \\
\text { week will reduce the risk of cancer recurrence? }\end{array}$ & $81 \%$ & $83.3 \%$ & $85,4 \%$ \\
\hline $\begin{array}{l}\text { Do you need follow-up with your primary care provider for prevention } \\
\text { services to reduce your risk of developing diseases and cancers? }\end{array}$ & $88.1 \%$ & $100 \%$ & $100 \%$ \\
\hline Are you aware of support groups in the community? & $57.1 \%$ & $83.3 \%$ & $85.4 \%$ \\
\hline $\begin{array}{l}\text { Do you know who to call if you are concerned about cancer } \\
\text { recurrence? }\end{array}$ & $61.9 \%$ & $100 \%$ & $95.1 \%$ \\
\hline Do you know the symptoms of cancer recurrence? & $19 \%$ & $85.7 \%$ & $61 \%$ \\
\hline
\end{tabular}


Medical Outcomes Study Short Form-36 (MOS-SF-36) Questionnaire. All participants completed the MOS-SF-36 Questionnaire pre-SCP intervention, and 41 participants completed this Questionnaire at the follow-up clinic visit. There were no statistically significant changes in health-related quality of life between the two time points (Table 7).

Table 7. MOS-SF-36 Subscale Scores from Pre- to Post- SCP Intervention. (N = 41)

\begin{tabular}{lccccc}
\hline & Pre & Post $^{1}$ & Mean & & \\
\hline MOS-SF-36 Subscale & $M(S D)$ & $M(S D)$ & Difference & \multicolumn{1}{c}{} & \multicolumn{1}{c}{$p$} \\
Physical functioning & $68.9(26.8)$ & $69.6(26.8)$ & 0.7 & 0.172 & 0.864 \\
Role functioning/ physical & $55.5(46.3)$ & $64.0(43.3)$ & 8.5 & 1.361 & 0.181 \\
Role functioning/ emotional & $61.0(45.9)$ & $67.5(42.5)$ & 6.5 & 0.860 & 0.395 \\
Energy/fatigue & $58.1(23.1)$ & $57.9(19.9)$ & -0.1 & -0.034 & 0.973 \\
Emotional well-being & $70.1(22.9)$ & $73.6(19.5)$ & 3.5 & 1.060 & 0.295 \\
Social functioning & $73.2(24.6)$ & $76.5(22.0)$ & 3.4 & 0.864 & 0.393 \\
Pain & $67.3(29.1)$ & $67.2(24.2)$ & -0.1 & -0.031 & 0.976 \\
General health & $59.8(21.7)$ & $64.6(20.7)$ & 4.9 & 1.537 & 0.132 \\
\hline
\end{tabular}

$(M=$ mean; $S D=$ standard deviation $)$

Patient Satisfaction Questionnaire - Short Form (PSQ-18). All participants completed the PSQ-SF-18 at baseline; 41 participants completed this form at the follow-up study clinic visit.

There were no statistically significant changes in satisfaction with delivery of health care from pre- to post-SCP intervention (Table 8).

Table 8. PSQ-SF-18 Subscale Scores Pre- Post- SCP Intervention. $(\mathrm{N}=41)$

\begin{tabular}{lccccc}
\hline & Pre & Post $^{\mathbf{1}}$ & Mean & & \\
\hline PSQ-SF-18 Subscales & $M(S D)$ & $M(S D)$ & Difference & \multicolumn{1}{c}{$t$} & \multicolumn{1}{c}{$p$} \\
General Satisfaction & $4.34(0.68)$ & $4.32(0.73)$ & -0.02 & -0.213 & .832 \\
Technical Quality & $3.90(0.55)$ & $3.80(0.67)$ & -0.09 & -0.948 & .349 \\
Interpersonal Manner & $3.84(0.77)$ & $3.85(0.83)$ & 0.01 & 0.086 & .932 \\
Communication & $4.11(0.78)$ & $4.01(0.68)$ & -0.10 & -0.752 & .457 \\
Financial Aspects & $3.85(0.77)$ & $3.90(0.74)$ & 0.05 & 0.413 & .682 \\
Time Spent with Doctor & $3.63(0.83)$ & $3.63(0.95)$ & 0.00 & 0.000 & 1.00 \\
Accessibility \& Convenience & $3.63(0.77)$ & $3.60(0.77)$ & -0.03 & -0.272 & .787 \\
\hline
\end{tabular}

Note: A higher PSG-SF-18 subscale score indicates greater satisfaction with delivery of health care; $M=$ mean; $S D=$ standard deviation

Adherence to SCP Follow-up Visits and Surveillance Testing. All 42 study participants returned for their follow-up visit. Forty participants (95.2\%) returned as scheduled. Two of the 
participants $(4.8 \%)$ re-scheduled the follow-up visit within 30 days of the original appointment due to family emergencies.

Open-Ended Evaluative Questionnaire (OEEQ). At the follow-up study clinic visit, 41 participants completed the OEEQ. A thematic networks analysis was used to extract emerging themes (Terry, 2015, pg. 205). OEEQ Question 1, "Please describe your experience with the delivery of the survivorship care plan", was answered by 41 participants. Emerged themes are presented in Figure 3.

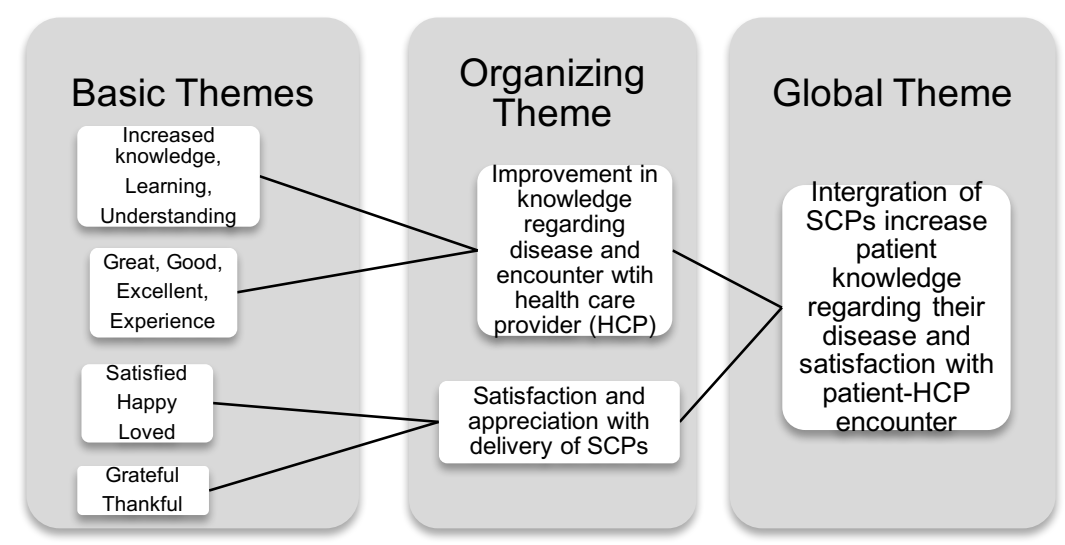

Figure 3. Emerged Themes from QEEQ-Question 1

OEEQ Question 2, "Since receiving the information in the survivorship care plan, have you made changes to your health?" responses resulted in $80.5 \%$ of participants answering "yes" to the question. Figure 4 describes the themes that emerged from the participant's narrative responses.

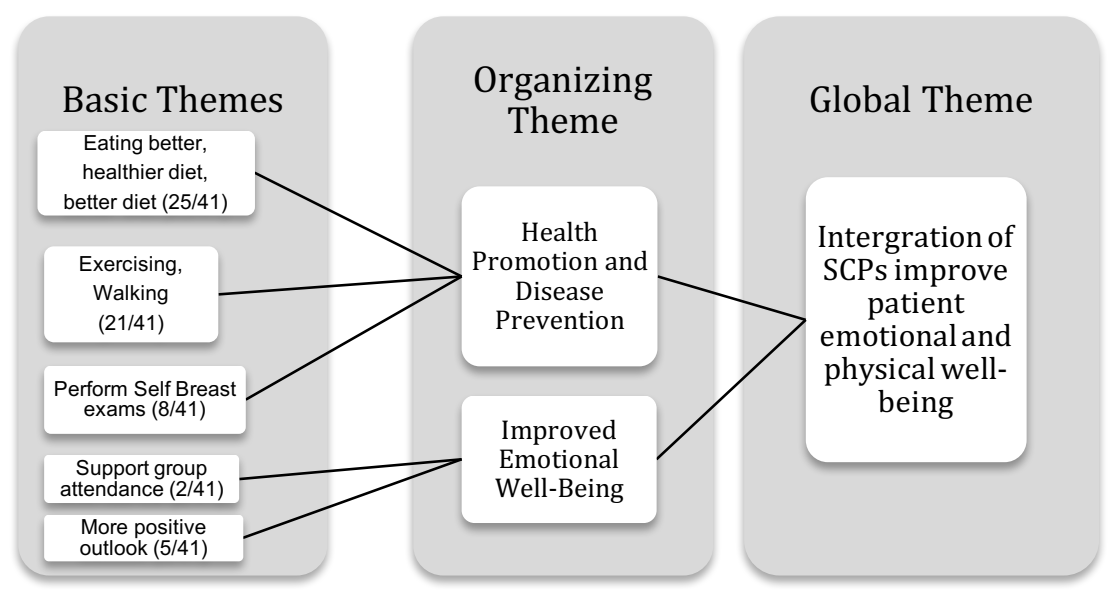

Figure 4. Emerged Themes from OEEQ-Question 2 
Some of the individual responses conveyed in OEEQ 2 were: 1) " I learn to live one day at a time"; 2) "I try to help others with cancer"; and "I have a positive attitude all the time and keep trusting in God."

Clinical Data Form II. No participant had a recurrence of cancer at the follow-up visit. Four participants $(9.5 \%)$, reported new co-morbidities from baseline visit which were tinea corporis, herpes zoster, coronary artery disease with new stent placement, and osteoporosis. 


\section{Chapter V}

\section{Discussion}

The SCP has been recommended by the IOM as a core measure of the ASCO Quality Oncology Practice Initiative (QOPI), and implementation of the SCP is a standard of the ACS $\mathrm{CoC}$ at the completion of intent-to-cure treatment for stage I, II, and III cancer patients (Hewitt, Greenfield, \& Stovall, 2006; Morgan, 2009). There remained a paucity of evidence to support the inclusion of SCPs into standard oncology patient care, which warranted further research to build the evidence base for practice.

This quality improvement project had multiple aims. The primary purpose was to integrate the SCPs into standard care for adult, stage I, II, and III breast and colon cancer patients following completion of initial cancer treatment at the Western US hospital clinical site to maintain the ASC CoC 2016 standards for accreditation as a cancer center. Secondary aims were to examine the hypothesis that following receipt of the SCP, participants' knowledge base would increase regarding their cancer, health promotion and disease prevention, satisfaction with health care delivery, quality of life, and adherence to follow-up visits and surveillance testing.

\section{Interpretation of the Result}

Provision of SCP. The primary purpose of integrating the SCPs into standard practice for eligible patients has been met. SCPs were delivered to 42 stage I, II, and III breast and colon cancer patients, who had completed their intent-to-cure treatment, over a four-month period of time. If the SCP continues to be integrated into practice at this same rate, the cancer program will have met the ASC CoC standard of providing SCPs to 25 percent of eligible patients by year end 2016. This SCP time period allowed easy integration into the busy Medical Oncology Clinic schedule after buy-in from all key project stakeholders. 
Compliance with Follow-up and Diagnostic Testing. One hundred percent of the study participants were compliant with their follow-up visits and surveillance testing, albeit a delay within 30 days of scheduled appointments by two of the the participants due to personal emergencies. This compliance rate is much higher than the current rate within the Medical Oncology Clinic, which regularly has a daily patient no-show rate of about 16 percent (personal communication T. Titus, October 17, 2016). However, it must be noted that the typical no-show rate within the Medical Oncology Clinic is a representation of new and follow-up visits, which include patients with all types and stages of cancer, and benign hematological conditions.

The sample sociodemographic characteristics (Table 3) are representative of the population seen at the Medical Oncology Clinic. The study participants are impoverished, making less than national poverty level income, unemployed/retired, and marginally educated. Despite these social disparities, the fact that these study participants were compliant with their scheduled visits is a testament to the impact of the knowledge conveyed within the SCP discussion of the importance of surveillance following completion of cancer treatment.

Patient Knowledge of Disease Questionnaire. Significant increase in participant's knowledge of disease was seen in participants following SCP implementation. Interestingly, there was an increase in score seen for each item of the PKDQ. Although, there was a reduction from baseline to the follow-up period in the PKDQ total score, the trend still remained high and statistically significant. This supports the use of the SCP to re-inform patients of their cancer diagnosis, and to inform cancer survivors of the recommendations for follow-up care, guidelines for health promotion and disease prevention, and use of support services, to improve their health and HRQOL. 
MOS-SF-36 and PSQ-18 Questionnaires. These two questionnaires did not show statistical significance between the baseline and follow-up visit. These results may have been related to numerous limitations. The first limitation was the small sample size. Second, there were only pre/post time and one follow up time point with a short time period. Third, many of the participants had just completed intent-to-cure treatment and were still experiencing significant treatment-related symptoms. And lastly, the PSQ-18 questionnaire assessed satisfaction with healthcare providers (HCPs), in general, not specifically with the healthcare received by HCPs at the Medical Oncology Clinic. The clinics and the hospital have long wait times due to providing healthcare services to a large metropolitan community, which may have contributed to the PSQ18 results.

Open-Ended Evaluative Questionnaire (OEEQ). The emerged themes from the OEEQ support SCP utility in increasing participants' knowledge, satisfaction with the HCP encounter and the receipt of the SCP, improved self-management of health and recognition of importance of support. Other interesting themes that emerged included existentialism, altruism, and faith ("living one day at a time", "helping others", trusting in God"). All participants expressed a positive comment pertaining to their experience with the delivery of the SCP. Themes which emerged from the thematic network analysis added to our understanding of the participants' experience with the SCP.

Clinical Data Form II. The time period between baseline and the follow-up visit was +/three months. This is a short period of time to show a recurrence of cancer within this small sample of participants. Of the four participants who noted new co-morbidities, two were selflimiting, one was a treatment for a known disease state, and the participant with the newly diagnosed osteoporosis was found when it was realized during the SCP visit that a bone density 
screening was needed due to her age, and also that she had been started on an aromatase inhibitor, post intent-to-cure breast cancer treatment.

\section{Comparison to Other Studies}

An exhaustive search of the evidence did not reveal any research study that has investigated the use of and outcomes of SCPs in a disadvantaged population, similar to this study. A few studies investigated participant satisfaction with and usefulness of the provision of the SCP.

The participants in the study by Palmer et al. (2015) were primarily white, well-educated, mid-upper socioeconomic class. Palmer et al. (2015) showed that SCPs were valued and used to make informed health behavior choices by breast cancer survivors, especially when the provision of the SCP was used by the women closer to diagnosis and treatment. Sprague et al. (2013) studied 58 breast and colorectal cancer patients with similar educational and socioeconomic characteristics to Palmer et al. (2015). The study participants in Sprague et al. (2013) were highly satisfied with the provision of the SCP designed from the Survivorship Care Plan Builder from Journey Forward. The 10 subjects investigated by Jefford et al. (2011) were either educated at the high school or college level, and primarily employed (70\%). The participants reported that the SCP was "useful, relevant, and convenient" (pg. E9).

The results of this study differ from the findings reported by Grunfeld et al (2011), who evaluated the effect of providing SCPs to 408 early stage breast cancer patients in a multi-center, randomized clinical trial, conducted in Canada. The majority of the participants were married, and high school or college graduates. Income data was not provided in the demographic profile. There were no statistically significant differences in the PSQ-18 and the MOS-SF-36 between 
the groups of participants following the provision of the SCP throughout a 12-month follow-up period. The study arms did not have large enough sample sizes to show statistical significance.

\section{Limitations}

This pilot study is limited due to its quasi-experimental design, small sample size, and only one follow-up time-point. The participants were consented during a scheduled SCP visit. This purposive sampling has a risk of researcher bias. The SCP program builders are currently provided only in the English language. The SCP provides critical information to cancer survivors regarding health promotion and disease prevention, support services, and follow-up surveillance recommendations. A SCP that can be translated into the primary language of the cancer survivor is urged.

\section{Barriers to Implementation}

There were few barriers to implementation. However, IRB approval from both the Georgetown University IRB and from the clinical site IRB created a delay to study start-up. Following IRBs' approval, the, study start-up was smooth and uneventful. The SCP visits were scheduled one to two afternoons per week. This afternoon scheduling requirement did not allow for flexibility for patients who required an AM appointment, limiting implementation of the SCP to all eligible patients.

Time Constraints. The 30 to 40-minute time period to build each patient's, tailored SCP and the 60-minute time frame to deliver the SCP was time-consuming and has been a barrier to the implementation of SCPs for oncology practices. To assist in this demanding process, the tumor registrars and an oncology registered nurse were assigned to assist in building the SCP. The DNP scholar reviewed the accuracy of the SCP data. The delivery of the SCP to each participant went without hindrance. 
Cost Constraints. Reimbursement for delivery of the SCP still remains an oncology practice barrier. There is still a gap between the requirement for implementation of the SCP to cancer patients and the reimbursement by payers of health care for the time needed to effectively construct the SCP and deliver it to patients. Great strides were made in meeting this challenge through using the correct evaluation and management billing code and correctly documenting the encounter and the time spent in patient counseling in the medical record. Reimbursement for constructing the SCP still remains a challenge for the oncology practice.

\section{Implications for Nursing Practice}

Integration of SCPs into standard care can be managed with appropriate planning by a nurse practitioner-led team. This project demonstrated that a nurse practitioner-led coordinated team of registered nurses, tumor registrars, clinic assistants, and patient navigators is able to plan, schedule, construct, and deliver SCPs effectively and efficiently to cancer survivors. This team approach was responsible for the successful integration of SCPs into practice and will be necessary as we move forward into 2017 and 2018, when ACS CoC accredited cancer centers will need to provide SCPs to 50 percent and 75 percent of stage I, II, and III cancer survivors, respectively. The model used in this study will be recommended to the study site's administration to meet the ASC CoC standard.

An additional positive outcome was that this study also met the ACS CoC standard for accreditation as a cancer center for year 2016. This quality improvement, nurse-led study was commended by nursing administration at the hospital affiliated with the Medical Oncology Clinic. Both the IRB and nursing administration are supporting more quality improvement studies designed and conducted by doctoral prepared nurses. 


\section{Summary and Suggestions for the Future}

Miller, et al. (2016) report that there were more than 15.5 million American cancer survivors on January 1, 2016 and it is predicted that by January 1, 2026, the number of cancer survivors will reach more than 20 million in the U.S. At the time of a cancer diagnosis, the patient and family are in a state of shock. The mere mention of the diagnosis numbs the mind from hearing the facts of the disease including stage, treatment, recurrence risks, and long-term side-effects of the cancer treatment. As these cancer survivors move through their survivorship journey, it is imperative that the patient and his/her primary health care provider remain knowledgeable about their cancer diagnosis, treatment of disease, cancer surveillance recommendations, health promotion, disease prevention, symptoms of cancer recurrence, management of long-term side-effects from treatment, and available support resources. The ideal time to provide this information is at the completion of intent-to-cure cancer treatment. This "teachable moment", comes at a time when the patient and family member are relieved that the the treatment is behind and they can move forward with survivorship. In this quality improvement project, the provision of the SCP, provided by a nurse practitioner over a one-hour time period, successfully accomplished the recommendation of the IOM and the standard for accreditation by the ASC CoC.

The underserved, high-risk population served at this Western US hospital are challenged by poverty, English as a second language, lack of educational opportunities, and racial/ethnic diversity. The SCP provided important information for this special population. However, it is important to provide the SCP translated into Spanish for the Latino cancer survivors as suggested by Ashing et al. (2014). Being culturally responsive to our English language limited patients by providing the patient informative piece of the SCP written in their native language, specifically 
the recommended surveillance and follow-up care care, management of side-effects, disease prevention, health promotion and available resources, is recommended (Ashing, 2014). Until this can be accomplished, it is important that the SCP visit includes a translator who can confirm that the cancer survivor comprehended the SCP information.

\section{Conclusion}

As ACS CoC accredited cancer centers strive to accomplish the standards of accreditation, and cancer centers fulfill the recommendations of the IOM and the ASCO Quality Oncology Practice Initiative, the delivery of the SCP will continue to be debated within the professional oncology community. This study showed that integration of the SCP into standard care in this low socio-economic, ethnically diverse sample increased participants' knowledge regarding their cancer disease process, and promoted adherence to follow-up exam and surveillance visits. Participants expressed a positive experience with the SCP process. Results warrant further examination of SCP integration into standard care, and its effects on HRQOL and patient satisfaction with healthcare delivery through a fully powered study of longer duration with patients from underserved populations with diverse cancer diagnoses. The oncology nurse practitioner is a key member of the health team promoting the integration of the SCP into standard oncology care. 


\section{References}

Agency for Healthcare Research and Quality (2002). Systems to rate the strength of scientific evidence. (AHRQ Publications No. 02-E016). Rockville, MD. Retrieved from http://archive.ahrq.gov/clinic/epcsums/strengthsum.htm

American College of Surgeons: Commission on Cancer. Cancer Program Standards 2012:

Ensuring Patient-Centered Care. Chicago, Ill. (pp. 78 \& 107). Retrieved from https://www.facs.org/ /media/files/quality $\% 20$ programs/cancer/coc/programstandards20

$\underline{12}$

Ashing-Giwa, K., Tapp, C., Brown, S., Fulcher, G., Smith, J., Mitchell, E., Santifer, R...Jackson, P. A. (2013). Are survivorship care plans responsive to African-American breast cancer survivors?: voices of survivors and advocates. Journal of Cancer Survivor, 7, 283-291.

Birken, S. A., Ellis, S. D., Walker, J. S., DiMartino, L. D., Check, D. K., Gerster, A. A., \& Mayer, D. K. (2015). Guidelines for the use of survivorship care plans: a systematic quality appraisal using the AGREE II instrument. Implementation Science, 10(63). doi: $10.1186 / \mathrm{s} 13012-015-0254-9$

Blanch-Hartigan, D., Forsythe, L. P., Alfano, C. M., Smith, T., Nekhlyudov, L., Ganz, P., \& Rowland, J. H. (2014). Provision and discussion of survivorship care plans among cancer survivors: results of a nationally representative survey of oncologists and primary care physicians. Journal of Clinical Oncology, 32(15), 1578-1585.

Bousquet, J., Knani, J., Dhivert, H., Richard, A., Chicoye, A., Ware, J, \& Michel, F-B. (1994). Quality of life in asthma. I. Internal consistency and validity of the SF-36 questionnaire. American Journal of Respiratory Critical Care Medicine, 149, 371-375. 
Cowens-Alvarado, R., Sharpe, K., Pratt-Chapman, M., Willis, A., Gansler, T., Ganz, P. A.,...Stein, K. (2013). Advancing survivorship care through the National Cancer Survivorship Resource Center: Developing American Cancer Society guidelines for primary care providers. CA: A Cancer Journal for Clinicians, 63:147-150. Retrieved from http://onlinelibrary.wiley.com/doi/10.3322/caac.21183/full

Dang, D., Melnyk, B. M., Fineout-Overholt, E., Cilista, D., DiCenso, A., Cullen, L.,...Stevens, K. R. (2015). Models to guide implementation and sustainability of evidence-based practice. In B. M. Melnyk \& E. Fineout-Overholt (Eds.), Evidence-Based Practice in Nursing and Healthcare: A Guide to Best Practice ( $3^{\text {rd }}$ ed., pp. 274-315). Philadelphia, PA: Wolters Kluwer Health.

Donabedian, A. (1988). The quality of care: How can it be assessed? JAMA, 260, 1743-1748. Dulko, D., Pace, C. M., Dittus, K. L., Sprague, B. L., Pollack, L. A., Hawkins, N. A., \& Geller, B. M. (2013). Barriers and facilitators to implementing cancer survivorship care plans. Oncology Nursing Forum, 40(2), 575-580.

Ganz, P. A., Kwan, L., Somerfield, M. R., Alberts, D., Garber, J., Offit, K. \& Scott, M. (2006). The role of prevention in oncology practice: Results from a 2004 survey of American Society of Clinical Oncology members. Journal of Clinical Oncology, 24, 2948-2957.

Grunfeld, E., Julian, J. A., Pond, G., Maunsell, E., Coyle, D., Folkes, A., Joy, A. A.,...Levine, M. N. (2011). Evaluating survivorship care plans: results of a randomized, clinical trial of patients with breast cancer. Journal of Clinical Oncology, 29(36), 4755-4762. doi: 10.1200/JCO.2011.36.8373

Hahn, E. E. \& Ganz, P. A. (2011). Survivorship programs and care plans in practice: variations on a theme. Journal of Oncology Practice: 7(2), 70-75. 
Haq, R., Heus, L., Baker, N., A., Dastur, D., Leung, F.-K., Leung, E.,...Parsons, J.A. (2013). Designing a multifaceted survivorship care plan to meet the information and communication needs of breast cancer patients and their family physicians: results of a qualitative pilot study. BMC Medical Informatics and Decision Making, 13(76).

Hausman, J., Ganz, P. A., Sellers, T. P., \& Rosenquist, J. (2011). Journey Forward: The new face of cancer survivorship care. Journal of Oncology Practice, 7(suppl 3):e50s-e56s.

Hewitt, M., Greenfield, S., \& Stovall, E. (Eds.) (2006). From Cancer Patient to Cancer Survivor: Lost in Transition. The National Academies Press. Washington, DC.

Jefford, M., Lotfi-Jam, K., Baravelli, C., Grogan, S., Rogers, M., Krishnasamy, M.,...Schofield, P. (2011). Development and pilot testing of a nurse-led posttreatment support package for bowel cancer survivors. Cancer Nursing, 34(3), E1-E10.

Kotter, J. P. \& Cohen, D. S. (2012). The Heart of Change: Real life Stories of how people change their organizations. Boston, MA: Harvard Business School Press.

Malin, J., Sayers, E-J, \& Jefford, M. (2011). What Is Quality Health Care for Cancer Survivors? In Feuerstein, M, and Ganz, P. (Eds.). Health Services for Cancer Survivors. 27-49. Springer.

Mayer, D. K., Birken, S. A, Check, D. K., \& Chen, R, C. (2014). Summing it up: an integrative review of studies of cancer survivorship care plans (2006-2013). Cancer, 121(7), 978996.

Mayer, D. K., Nekhlyudov, L., Snyder, C. F., Merrill, J. K., Wollins, D. S., \& Shulman, L. N. (2014). American Society of Clinical Oncology Clinical Expert Statement on Cancer Survivorship Care Planning. Journal of Oncology Practice. Advance online publication. doi: 10.1200/JOP.2014.00132 
Mariotto, A. B., Yabroff, K. R., Shao, Y., Feuer, E. J., \& Brown, M. L. (2011). Projections of the cost of cancer in the United States: 2010-2020. Journal of the National Cancer Institute, 103(2), 117-128.

McCabe, M. S., Bhatia. S., Oeffinger, K. C., Reaman, G. H., Tyne, C., Wollins, D. S., \& Hudson, M. M. (2013). American Society of Clinical Oncology Statement: Achieving high-quality cancer survivorship care. Journal of Clinical Oncology, 31(5), 631-640. doi: $10.1200 / J C O .2012 .46 .6854$

McDowell, M. E., Occhipinti, S., Ferguson, M., Dunn, J., and Chambers, S. K. (2010). Predictors of change in unmet supportive care needs in cancer. Psycho-Oncology, 19, 508-516.

Melnyk, B. M., Morrison-Beedy, D. \& Cole, R. (2015). Generating evidence through quantitative research. In B. M. Melnyk, \& E. Fineout-Overholt (Eds.), Evidence-Based Practice in Nursing \& Healthcare: A Guide to Best Practice ( $3^{\text {rd }}$ ed., pp. 439-475). Philadelphia, CA: Wolters Kluwer Health.

Moran, K. \& Burson, R. (2014). The phenomenon of interest. In K. Moran, R. Burson, \& D. Conrad (Eds.), The Doctor of Nursing Practice Scholarly Project: A Framework for Success (pg. 87-108). Burlington, MA: Jones \& Bartlett Learning.

Morgan, M. A. (2009). Cancer survivorship: History, quality-of-life issues, and the evolving multidisciplinary approach to implementation of cancer survivorship care plans. Oncology Nursing Forum, 36, 429-436.

Palmer, S. C., Stricker, C. T., Panzer, S. L., Arvey, S. A., Baker, K. S., Casillas, J., Ganz, P.,... Jacobs, L. A. (2015). Outcomes and satisfaction after delivery of a breast cancer 
survivorship care plan: results of a multicenter trial. Journal of Oncology Practice, 11(2), 222-226. doi: 10.1200/JOP.2014.001404

Rosswurm, M. A. \& Larrabee, J. (1999). A model for change to evidence-based practice. Image: Journal of Nursing Scholarship, 31(4), 317-322.

Rouen, P. (2014). Aligning design, method, and evaluation with the clinical question. In K. Moran, R. Burson, \& D. Conrad (Eds.), The Doctor of Nursing Practice Scholarly Project: A Framework for Success (pp. 331-346). Burlington, MA: Jones \& Bartlett Learning.

Schein, E. H. (1984). Coming to a new awareness of organizational culture. Sloan Management Review, 25, 3-16.

Shirey, M. (2006). Evidence-based practice: how nurses can facilitate innovation, Nursing Administration Quarterly, 30, 252-265.

Sprague, B. L., Dittus, K. L., Pace, C. M., Dulko, D., Pollack, L. A., Hawkins, N. A., \& Geller, B. M. (2013). Patient satisfaction with breast and colorectal cancer survivorship plans. Clinical Journal of Oncology Nursing, 17(3), 266-272.

Stillwell, S. B., Fineout-Overholt, E., Melnyk, B. M., \& Williamson, K. M. (2010). Evidencebased practice, step by step: Asking the clinical question: A key step in evidence-based practice. American Journal of Nursing, 110(3), 58-61.

Talento, B. (1995). Jean Watson. In J. George (Ed.), Nursing Theories: The Base for Professional Nursing Practice ( $4^{\text {th }}$ ed., pp. 317-333). Norwalk, CT: Appleton \& Lange. Taylor, K \& Monterosso, L. (2015). Survivorship care plans and treatment summaries in adult patients with hematologic cancer: an integrative literature review. Oncology Nursing Journal, 42(3), 283-291. 
Terry, A. J. (2015). Conducting a literature review. In A. Terry (Ed.), Clinical Research for the Doctor of Nursing Practice ( $2^{\text {nd }}$ ed., pp. 47-60). Burlington, MA: Jones \& Bartlett.

Terry, A. J. (2015). Data analysis. In A. Terry (Ed.), Clinical Research for the Doctor of Nursing Practice ( $2^{\text {nd }}$ ed., pp. 197-209). Burlington, MA: Jones \& Bartlett.

Twombly, R. (2004). What's in a Name: Who Is a Cancer Survivor?. Journal of National Cancer Institute, 96(19), 1414-1415.

Ware, J. E. \& Sherbourne, C. D. (1992). The MOS 36-item short-form health survey (SF:36): I. Conceptual framework and item selection. Medical Care, 30, 473-483.

Weir, H. K., Thompson, T. D., Soman, A., Møller, B. \& Leadbetter, S. (2015). The past, present, and future of cancer incidence in the United States: 1975 through 2020. Cancer, 121(11), 1827-1837. doi: 10.1002/cncr.29258 